OPEN ACCESS

Edited by:

Carol Mason,

Columbia University, United States

Reviewed by:

Victoria P. Connaughton,

American University, United States

C. Peter Bengtson

Heidelberg University, Germany

*Correspondence:

Wallace B. Thoreson wbthores@unmc.edu

Received: 17 March 2017 Accepted: 26 June 2017 Published: 11 July 2017

Citation: Grassmeyer JJ and Thoreson WB (2017) Synaptic Ribbon Active Zones in Cone Photoreceptors Operate Independently from One Another.

Front. Cell. Neurosci. 11:198. doi: 10.3389/fncel.2017.00198

\section{Synaptic Ribbon Active Zones in Cone Photoreceptors Operate Independently from One Another}

\author{
Justin J. Grassmeyer ${ }^{1,2}$ and Wallace B. Thoreson ${ }^{1,2 *}$ \\ ${ }^{1}$ Department of Pharmacology and Experimental Neuroscience, University of Nebraska Medical Center, Omaha, NE, \\ United States, ${ }^{2}$ Truhlsen Eye Institute and Department of Ophthalmology and Visual Sciences, University of Nebraska Medical \\ Center, Omaha, NE, United States
}

Cone photoreceptors depolarize in darkness to release glutamate-laden synaptic vesicles. Essential to release is the synaptic ribbon, a structure that helps organize active zones by clustering vesicles near proteins that mediate exocytosis, including voltagegated $\mathrm{Ca}^{2+}$ channels. Cone terminals have many ribbon-style active zones at which second-order neurons receive input. We asked whether there are functionally significant differences in local $\mathrm{Ca}^{2+}$ influx among ribbons in individual cones. We combined confocal $\mathrm{Ca}^{2+}$ imaging to measure $\mathrm{Ca}^{2+}$ influx at individual ribbons and patch clamp recordings to record whole-cell $\mathrm{I}_{\mathrm{Ca}}$ in salamander cones. We found that the voltage for half-maximal activation $\left(\mathrm{V}_{50}\right)$ of whole cell $\mathrm{I}_{\mathrm{Ca}}$ in cones averaged $-38.1 \mathrm{mV} \pm 3.05 \mathrm{mV}$ (standard deviation [SD]), close to the cone membrane potential in darkness of ca. $-40 \mathrm{mV}$. $\mathrm{Ca}^{2+}$ signals at individual ribbons varied in amplitude from one another and showed greater variability in $V_{50}$ values than whole-cell $I_{\mathrm{Ca}}$, suggesting that $\mathrm{Ca}^{2+}$ signals can differ significantly among ribbons within cones. After accounting for potential sources of technical variability in measurements of $\mathrm{Ca}^{2+}$ signals and for contributions from cone-to-cone differences in $I_{\mathrm{Ca}}$, we found that the variability in $V_{50}$ values for ribbon $\mathrm{Ca}^{2+}$ signals within individual cones showed a SD of $2.5 \mathrm{mV}$. Simulating local differences in $\mathrm{Ca}^{2+}$ channel activity at two ribbons by shifting the $\mathrm{V}_{50}$ value of $\mathrm{I}_{\mathrm{Ca}}$ by $\pm 2.5 \mathrm{mV}$ (1 SD) about the mean suggests that when the membrane depolarizes to $-40 \mathrm{mV}$, two ribbons could experience differences in $\mathrm{Ca}^{2+}$ influx of $>45 \%$. Further evidence that local $\mathrm{Ca}^{2+}$ changes at ribbons can be regulated independently was obtained in experiments showing that activation of inhibitory feedback from horizontal cells (HCs) to cones in paired recordings changed both amplitude and $\mathrm{V}_{50}$ of $\mathrm{Ca}^{2+}$ signals at individual ribbons. By varying the strength of synaptic output, differences in voltage dependence and amplitude of $\mathrm{Ca}^{2+}$ signals at individual ribbons shape the information transmitted from cones to downstream neurons in vision.

Keywords: ribbon synapse, retina, exocytosis, calcium imaging, cone photoreceptor, active zone

\section{INTRODUCTION}

Photoreceptors release glutamate-laden vesicles at rates continuously regulated by graded, light-driven changes in membrane voltage $\left(V_{\mathrm{m}}\right)$. To sustain this continuous and abundant output, the number of vesicles in a photoreceptor terminal exceeds that of a conventional hippocampal synapse by more than two orders of magnitude and photoreceptors possess 
specialized presynaptic structures called ribbons that organize and coordinate vesicular release (Sterling and Matthews, 2005; Schmitz, 2009). Cones can have up to 50 ribbon-style active zones that are typically separated from one another by $500 \mathrm{~nm}$ or more within the synaptic terminal (DeVries et al., 2006), while mammalian rods generally possess only a single ribbon (Carter-Dawson and LaVail, 1979; Sterling and Matthews, 2005). Synaptic vesicles are tethered to a ribbon by thin filaments but can move freely along the ribbon surface (Graydon et al., 2014). Beneath each ribbon sits a cluster of L-type $\mathrm{Ca}^{2+}$ channels and other presynaptic proteins that control the exocytosis of synaptic vesicles (Mercer and Thoreson, 2011; Lv et al., 2016; Maxeiner et al., 2016). Ribbon-localized $\mathrm{Ca}^{2+}$ channels mediate nearly all of the photoreceptor $\mathrm{Ca}^{2+}$ current ( $\mathrm{I}_{\mathrm{Ca}}$; Mansergh et al., 2005; Xu and Slaughter, 2005; Mercer and Thoreson, 2011). The opening of $\mathrm{Ca}^{2+}$ channels generates large increases in $\mathrm{Ca}^{2+}$ just beneath the ribbon, with the subsequent $\mathrm{Ca}^{2+}$ spread determined by both the magnitude of influx and intracellular buffering conditions (Choi et al., 2008; Van Hook and Thoreson, 2015). Vesicular release from cones, like many other CNS synapses (Brandt et al., 2005; Goutman and Glowatzki, 2007; Jarsky et al., 2010; Eggermann et al., 2011), is regulated by $\mathrm{Ca}^{2+}$ levels attained only within highly localized nanodomains adjacent to open $\mathrm{Ca}^{2+}$ channels (Bartoletti et al., 2011). Nanodomain control of release and the fact that ribbon-associated $\mathrm{Ca}^{2+}$ signals can remain spatially restricted from one another suggest that differences in $\mathrm{Ca}^{2+}$ dynamics among individual photoreceptor ribbons could diversify signals transmitted to postsynaptic neurons.

Ribbon-bearing cochlear inner hair cells exhibit significant differences in the amplitude and voltage dependence of ribbonlocalized $\mathrm{Ca}^{2+}$ signals that are thought to contribute to diversity in firing rate, sound threshold, and dynamic range among second-order spiral ganglion neurons (Frank et al., 2009; Ohn et al., 2016). Significant differences in $\mathrm{Ca}^{2+}$ influx arising from local differences in the function or subunit composition of $\mathrm{Ca}^{2+}$ channels at different hippocampal synapses have also been observed (Éltes et al., 2017). Voltage dependence might also vary at different synapses as a consequence of local differences in the ionic environment and neuromodulatory influence. Changes of only a few millivolts in the midpoint activation voltage $\left(\mathrm{V}_{50}\right)$ for $\mathrm{I}_{\mathrm{Ca}}$, such as those caused by inhibitory feedback from horizontal cells (HCs; Verweij et al., 1996), can produce functionally significant changes in synaptic output from cones. In this study, we asked whether ribbons within individual cones show functionally significant differences in the voltage dependence of ribbon-associated $\mathrm{Ca}^{2+}$ channels, allowing them to operate independently from one another. Alternatively, all ribbons within an individual cone may exhibit the same voltage dependence and function more like a single distributed ribbon.

To assess the functional independence of $\mathrm{Ca}^{2+}$ responses at individual ribbon synapses in cones, we combined whole-cell patch clamp recordings of $\mathrm{I}_{\mathrm{Ca}}$ with confocal imaging of individual ribbons in a vertical slice preparation of salamander retina. After accounting for cone-to-cone differences and potential technical sources of variability, we found significant intrinsic differences in the amplitude and voltage dependence of $\mathrm{Ca}^{2+}$ influx among ribbons within individual cones. In the absence of negative feedback from HCs, the intrinsic variability in $\mathrm{V}_{50}$ values among ribbons (standard deviation $[\mathrm{SD}]=2.5 \mathrm{mV}$ ) is sufficient to produce differences in $\mathrm{Ca}^{2+}$ influx at individual ribbons of $45 \%$ or more at a cone's resting membrane potential in darkness. We assessed the sensitivity of confocal $\mathrm{Ca}^{2+}$ measurements by manipulating extracellular $\mathrm{pH}$ to produce $3 \mathrm{mV}$ shifts in voltage dependence. By directly manipulating HC membrane potential in paired whole-cell recordings with cones, we confirmed the ability of ribbons operate independently by showing that inhibitory feedback from an individual $\mathrm{HC}$ was capable of altering $\mathrm{Ca}^{2+}$ responses at some ribbons but not others in a cone terminal (Thoreson and Mangel, 2012). In contrast to the traditional view that the membrane potential in cones in darkness sits near the foot of the $\mathrm{I}_{\mathrm{Ca}}$ activation curve (Barnes and Kelly, 2002), we found that the average $\mathrm{V}_{50}$ for whole-cell $\mathrm{I}_{\mathrm{Ca}}$ and ribbon $\mathrm{Ca}^{2+}$ signals was near the dark resting membrane potential. This arrangement is optimal for signaling small changes in voltage produced by small changes in illumination (Sterling and Laughlin, 2015). Ribbonto-ribbon differences in voltage dependence and amplitude of $\mathrm{Ca}^{2+}$ responses can produce ribbon-to-ribbon differences in synaptic gain and thus expand the transformations available to an individual cone for encoding light-evoked voltage responses into changes in synaptic release. This may improve the ability of a cone to signal luminance changes over a wide range of intensities.

\section{MATERIALS AND METHODS}

\section{Animal Care and Use}

All experiments were performed using ex vivo vertical slices of retina from aquatic tiger salamanders (Ambystoma tigrinum; Charles Sullivan Co., Nashville, TN, USA) of both sexes (18-25 cm in length). We used cones from salamander retina for these studies because the ribbons in these cells are sufficiently far apart to be distinguished by optical imaging and because the synaptic terminal sits at the base of the cell body where it can be effectively voltage-clamped. All animal care and handling protocols were approved by the University of Nebraska Medical Center Institutional Animal Care and Use Committee. Euthanasia was conducted in accordance with AVMA Guidelines for the Euthanasia of Animals. Salamanders were kept on a 12-h dark/light cycle at $4-8^{\circ} \mathrm{C}$.

\section{Slice Preparation}

One to two hours after onset of the dark cycle, salamanders were euthanized by decapitation and rapidly pithed. The eyes were enucleated, the retina isolated, and vertical retinal slices $(125 \mu \mathrm{m}$ thickness) were prepared as described in detail elsewhere (Van Hook and Thoreson, 2013).

\section{Patch Clamp Electrophysiology}

Throughout the experiments, the slice chamber was superfused at $\sim 1 \mathrm{ml} / \mathrm{min}$ with chilled amphibian saline solution bubbled with $100 \% \mathrm{O}_{2}$ (HEPES solution, standard conditions) or $95 \%$ $\mathrm{O}_{2} / 5 \% \mathrm{CO}_{2}\left(\mathrm{HCO}_{3}^{-}\right.$solution, when noted in text). The HEPESbuffered saline contained (in $\mathrm{mM}$ ): $116 \mathrm{NaCl}, 2.5 \mathrm{KCl}, 1.8 \mathrm{CaCl}_{2}$, $0.5 \mathrm{MgCl}_{2}, 5$ glucose and 10 HEPES. The $\mathrm{pH}$ of this solution 
was adjusted to 7.8 (or 7.6 when noted in text) with $\mathrm{NaOH}$. The bicarbonate-buffered solution contained (in $\mathrm{mM}$ ): $101 \mathrm{NaCl}$, $2.5 \mathrm{KCl}, 2.0 \mathrm{CaCl}_{2}, 0.5 \mathrm{MgCl}_{2}, 11$ glucose and $22 \mathrm{NaHCO}_{3}$. For both solutions, the osmolality was measured with a vapor pressure osmometer (Wescor) and if necessary adjusted to $\sim 245$ mOsm. Patch pipettes were pulled with a PP-830 or PC-10 vertical pipette puller (Narishige) from borosilicate glass pipettes (1.2 mm OD, $0.9 \mathrm{~mm}$ ID, with internal filament; World Precision Instruments) and had resistances of 9-15 M $\Omega$. For some experiments, pipette shafts were coated with dental wax to reduce stray capacitance. The intracellular pipette solution contained (in mM): 50 CsGluconate, 40 CsGlutamate, $10 \mathrm{TEACl}$, $3.5 \mathrm{NaCl}, 1 \mathrm{CaCl}_{2}, 1 \mathrm{MgCl}_{2}, 9.4 \mathrm{MgATP}$ and $0.5 \mathrm{GTP}-\mathrm{Na}$, 5 EGTA. After salts were dissolved, the $\mathrm{pH}$ was adjusted to 7.2 with $\mathrm{CsOH}$ (osmolality $=235-240 \mathrm{mOsm}$ ). All chemical reagents were from Sigma-Aldrich unless indicated otherwise.

Experiments were performed on an upright fixed-stage microscope (Nikon E600FN) under a water-immersion objective $(60 \times, 1.0 \mathrm{NA})$. Cells were identified morphologically and recording electrodes were positioned with Huxley-Wall micromanipulators (Sutter Instruments). After obtaining a gigaohm seal, the patch was ruptured with gentle suction. Photoreceptor and HC recordings were conducted in voltage clamp and were performed using Alembic VE-2 (Alembic Instruments) and Axopatch 200B (Axon Instruments/Molecular Devices) amplifiers, respectively. Cone membrane currents from the Alembic were low-pass filtered at $3 \mathrm{kHz}$ and $\mathrm{HC}$ currents from the Axopatch were filtered at $2 \mathrm{kHz}$. Some membrane currents were low-pass filtered at $200 \mathrm{~Hz}$ to facilitate data presentation. Signals were digitized with a Digidata 1322A (Axon Instruments, Molecular Devices) and acquired with pClamp 10 software (Molecular Devices). Series resistance was maximally compensated in every cone before recording using the Alembic amplifier, which allows stable compensation (Sherman et al., 1999).

Whole-cell $\mathrm{I}_{\mathrm{Ca}}$ was measured using a ramp voltage protocol ( -99 to $+51 \mathrm{mV}, 0.5 \mathrm{mV} / \mathrm{ms}$ ) applied from a steady holding potential of $-79 \mathrm{mV}$. Voltage-dependent and $\mathrm{Ca}^{2+}$-activated $\mathrm{K}^{+}$currents in cones were blocked by TEA in the pipette solution and hyperpolarizing-activated cation currents $\left(\mathrm{I}_{\mathrm{h}}\right)$ were inhibited by $\mathrm{Cs}^{+}$(Barnes and Hille, 1989). $\mathrm{Ca}^{2+}$-activated chloride currents were reduced by use of $5 \mathrm{mM}$ EGTA but also activate slowly during the ramp protocol and are therefore only evident after the voltage ramp has moved above $+20 \mathrm{mV}$ (unpublished observations). For determination of $\mathrm{V}_{50}$ values, passive membrane resistance was subtracted from ramp currents using $\mathrm{P} / 8$ subtraction. Comparison of currents obtained in the presence of and absence of $\mathrm{Cd}^{2+}(0.1 \mathrm{mM})$ yielded the same current/voltage profiles for photoreceptor $\mathrm{I}_{\mathrm{Ca}}$ (Stella and Thoreson, 2000). Consistent with earlier results (Stella and Thoreson, 2000), we also found that when we compared $\mathrm{I}_{\mathrm{Ca}}$ evoked during the sequence of voltage steps used for $\mathrm{Ca}^{2+}$ measurements (described below) to $\mathrm{I}_{\mathrm{Ca}}$ measured using the ramp voltage protocol ( $n=6$ cones), we observed the same voltage dependence with both measurements.

Most of the $\mathrm{Ca}^{2+}$ imaging experiments described in this study used $175 \mathrm{~ms}$ depolarizing steps applied from a steady holding potential of $-79 \mathrm{mV}$ ( -39 to $-19 \mathrm{mV}, 5 \mathrm{mV}$ increments) with $2 \mathrm{~s}$ between each step. We compared results obtained when the steps were applied in both forward and reverse order (forward: -39 to $-19 \mathrm{mV}$, reverse: -19 to $-39 \mathrm{mV}$ ). In trials where steps were applied in the forward order, ribbon $\mathrm{Ca}^{2+}$ signals yielded $\mathrm{V}_{50}$ values that were $2.06 \pm 1.38 \mathrm{mV}$ more positive than whole cell $\mathrm{I}_{\mathrm{Ca}}$ measured in the same cones ( $n=10$ ribbons, $n=7$ cones). In trials where steps were applied in the reverse order, ribbon $\mathrm{Ca}^{2+}$ signals yielded $\mathrm{V}_{50}$ values that were $2.17 \pm 0.97 \mathrm{mV}$ more negative than whole cell $\mathrm{I}_{\mathrm{Ca}}(n=10$ ribbons, $n=7$ cones). Values from the two different measurement sequences thus straddled the values for $\mathrm{I}_{\mathrm{Ca}}$. Photoreceptor $\mathrm{I}_{\mathrm{Ca}}$ in salamander rods shows slow and weak $\mathrm{Ca}^{2+}$-dependent inactivation $(\tau=1.7 \mathrm{~s}$; Corey et al., 1984; Rabl and Thoreson, 2002). To reduce the potential impact of $\mathrm{Ca}^{2+}$-dependent inactivation, we performed step series in the forward order. As addressed in the results, the more-positive $V_{50}$ values obtained when steps are applied in the forward direction results at least in part from using the low affinity $\mathrm{Ca}^{2+}$ dye that does not readily detect small $\mathrm{Ca}^{2+}$ changes at weak voltages. For some of the later experiments on HC to cone feedback, we also used a staircase protocol in which we did not return to baseline $(-79 \mathrm{mV})$ between test voltages to speed data acquisition during paired recordings. Voltage dependence measured with the two protocols did not differ noticeably.

Whole cell membrane resistance and capacitance in cones averaged $192 \pm 88.9 \mathrm{M} \Omega$ and $80 \pm 16.4 \mathrm{pF}$, respectively (mean $\pm \mathrm{SD}, n=47$ cones). We excluded recordings if the current needed to voltage clamp a cone at $-79 \mathrm{mV}$ exceeded $250 \mathrm{pA}$ or if the series resistance prior to compensation exceeded $60 \mathrm{M} \Omega$. When multiple recordings within a cell were compared or averaged (e.g., when comparing ramp $\mathrm{I}_{\mathrm{Ca}}$ with step-evoked $\mathrm{Ca}^{2+}$ signals), only trials with holding currents within $50 \mathrm{pA}$ of one another were compared. When multiple stimulus trials were conducted within a cell, we waited at least 1 min between trials. We corrected membrane voltage values for a measured liquid junction potential by subtracting $9 \mathrm{mV}$.

\section{Confocal $\mathrm{Ca}^{2+}$ Imaging}

Confocal imaging was performed with Nikon Elements software using a laser confocal scanhead (Perkin Elmer Ultraview LCI) equipped with a cooled CCD camera (Orca ER) mounted on the Nikon E600FN. Excitation at 488 or $568 \mathrm{~nm}$ was delivered from an argon/krypton laser and emission was collected at 525 or $600 \mathrm{~nm}$, respectively, by a cooled CCD camera (Hamamatsu OrcaER). Filters were controlled using a Sutter Lambda 10-2 filter wheel and controller. The objective was controlled using a E662 z-axis controller (Physik Instrumente). Cell-impermeant $\mathrm{Ca}^{2+}$ indicators Oregon Green 488 BAPTA-5N (OGB-5N, $K_{\mathrm{d}}=20 \mu \mathrm{M}$, Thermo Fisher) or Oregon Green 488 BAPTA-6F (OGB-6F, $K_{\mathrm{d}}=3 \mu \mathrm{M}$, Thermo Fisher) were added to the patch pipette solution at $400 \mu \mathrm{M}$. Images ( $57 \mathrm{~ms} /$ frame) were acquired during the voltage step protocol described above and analyzed using Nikon Elements 4.5 and Microsoft Excel software. Fluorescence values were measured as the mean pixel intensity within the region of interest (ROI). Baseline $\mathrm{Ca}^{2+}$ signal fluorescence was calculated by averaging signals during the first $1.3 \mathrm{~s}$ of the imaging trial when the photoreceptor was 
voltage clamped steadily at $-79 \mathrm{mV}$. Fluorescence changes $(\Delta \mathrm{F})$ evoked by depolarizing voltage steps were compared to baseline fluorescence $(\mathrm{F})$ and the resultant $\Delta \mathrm{F} / \mathrm{F}$ ratios were normalized to the largest fluorescence change in each trial before using nonlinear regression to determine $\mathrm{V}_{50}$ values (see Figure 1). Reduction in $\Delta \mathrm{F} / \mathrm{F}$ amplitude induced by activation of $\mathrm{HC}$ negative feedback during paired recordings was quantified by comparing the maximum $\mathrm{Ca}^{2+} \Delta \mathrm{F} / \mathrm{F}$ change in the absence of feedback to $\Delta \mathrm{F} / \mathrm{F}$ elicited by the same stimulus in the presence of feedback. Ribbons were defined as being subject to negative feedback if $\Delta \mathrm{F} / \mathrm{F}$ was reduced during $\mathrm{HC}$ depolarization in at least four out of five depolarizing steps $(-39$ to $-19 \mathrm{mV})$ in two consecutive trials.

We measured the optical resolution of our system using fluorescent microbeads. The full width half maxima (FWHM; $2.355 \times \mathrm{SD}$ ) of Gaussian functions fit to the fluorescence profiles in the $x-y$ plane averaged 318 and $455 \mathrm{~nm}$ for 525 and $600 \mathrm{~nm}$ emission, respectively. To measure resolution in the $\mathrm{z}$-axis, we acquired a $\mathrm{z}$-stack and measured the fluorescence profile as a function of depth. The FWHM in the z-axis averaged 1.45 and $1.46 \mu \mathrm{m}$ for 525 and $600 \mathrm{~nm}$ emission, respectively.

\section{Data Analysis}

Activation profile data from Clampfit, Nikon Elements, and Microsoft Excel was imported to GraphPad Prism to perform nonlinear regression, for statistical analyses, and to generate figures. To calculate $\mathrm{V}_{50}$ values and construct $\mathrm{I}_{\mathrm{Ca}}$ activation curves $\left(G / G_{\max }\right), \mathrm{Ca}^{2+}$ responses were fit with Boltzmann functions adjusted for $\mathrm{Ca}^{2+}$ driving force according to the equation

$$
I=\left(V_{\mathrm{rev}}-V_{\mathrm{m}}\right) * \frac{I_{\max }}{1+e^{\frac{\left(V_{50}-V_{\mathrm{m}}\right)}{k}}}
$$

where $V_{\text {rev }}=+41 \mathrm{mV}$ and $k$ is the slope factor of the voltagedependent activation process. $V_{\text {rev }}$ was the only constrained parameter. Distribution normality was assessed by D'AgostinoPearson Test. Data is reported as mean \pm SD unless indicated otherwise.

\section{RESULTS}

\section{Small Differences in the Activation of Ribbon $\mathrm{Ca}^{2+}$ Influx can be Detected}

To visualize $\mathrm{Ca}^{2+}$ influx at individual ribbon sites, we used spinning disk confocal microscopy while simultaneously controlling the membrane voltage of individual cones by voltage clamp. We introduced a low-affinity $\mathrm{Ca}^{2+}$ indicator, Oregon Green BAPTA-5N (OGB-5N, $K_{\mathrm{d}}=20 \mu \mathrm{M}$ ), into photoreceptors through the patch pipette and then evoked $\mathrm{Ca}^{2+}$ entry by delivering a series of depolarizing voltage steps. $\mathrm{Ca}^{2+}$ signals elicited in this way were typically constrained to hotspots near ribbons and only well-localized $\mathrm{Ca}^{2+}$ hotspots were analyzed (Zenisek et al., 2003; Choi et al., 2008; Frank et al., 2009; Mercer and Thoreson, 2011; Ohn et al., 2016). Figure 1A shows an example from one cone in which three $\mathrm{Ca}^{2+}$ hotspots were imaged simultaneously in the same confocal plane. Figure $\mathbf{1 A}_{1}$ shows an image obtained prior to depolarizing stimulation while panel $\mathbf{A}_{2}$ shows an image obtained during a depolarizing step to $-19 \mathrm{mV}$. Subtracting the image in panel $\mathbf{A}_{1}$ from that in $\mathbf{A}_{2}$ yielded the difference image shown in $\mathbf{A}_{3}$, in which three $\mathrm{Ca}^{2+}$ hotspots are clearly visible (arrows). In this cell, we also labeled ribbons by introducing a RIBEYE-binding peptide conjugated to tetramethylrhodamine (TAMRA) through the patch pipette (Zenisek et al., 2004). After recording a series of depolarizationinduced $\mathrm{Ca}^{2+}$ signals, we obtained a $\mathrm{z}$-stack image to visualize ribbons in the same cone. The three $\mathrm{Ca}^{2+}$ hotspots shown in Figure $\mathbf{1 A}_{3}$ correspond to three distinct fluorescently-labeled ribbons at the plane used for $\mathrm{Ca}^{2+}$ imaging (Figure $\mathbf{1} \mathbf{A}_{4}$ ). A fourth ribbon that was less strongly labeled was also visible in the same plane but did not produce a discrete $\mathrm{Ca}^{2+}$ hotspot.

Figure 1B illustrates the stimulation protocol used in this and most other experiments by showing ribbon-localized $\mathrm{Ca}^{2+}$ responses evoked with a series of depolarizing test steps for the three ribbons in Figure 1A. At each of these ribbons, $\mathrm{Ca}^{2+}$-dependent fluorescence rose quickly during each depolarizing step and then returned quickly to baseline after the step. The peak fluorescence change $(\Delta \mathrm{F} / \mathrm{F})$ elicited at each stimulation step was normalized to the maximum $\Delta \mathrm{F} / \mathrm{F}$ signal within each trial. The change in $\Delta \mathrm{F} / \mathrm{F}$ as a function of voltage was then fit with a Boltzmann function modified for $\mathrm{Ca}^{2+}$ driving force. Each ribbon site was analyzed independently. Figure 1C shows results from two consecutive stimulation trials in the same cone. In both trials, ribbons 1 and 2 showed a similar difference in voltage dependence from one another, with their half maximal voltage of activation $\left(\mathrm{V}_{50}\right)$ values differing by 3.67 and $3.15 \mathrm{mV}$ in trials 1 and 2, respectively. In trial 1 , the $V_{50}$ value for ribbon 1 fell outside the $95 \%$ confidence interval for ribbon 2 . The voltage dependence of ribbon 3 differed more between the two trials, with the difference in $\mathrm{V}_{50}$ between ribbons 1 and 3 increasing from $0.32 \mathrm{mV}$ to $2.70 \mathrm{mV}$ between trials 1 and 2 . In trial 2, the $\mathrm{V}_{50}$ value for ribbon 1 fell outside the $95 \%$ confidence interval for ribbon 3 and vice versa. Observations from eight other cones also showed reproducible differences in $\mathrm{V}_{50}$ values between ribbons in the same cone suggesting that the voltage dependence of ribbon $\mathrm{Ca}^{2+}$ responses may genuinely differ from one another. In the experiments described below, we quantified these $V_{50}$ differences after assessing various factors that might confound measurement accuracy.

\section{Evaluating Accuracy of Measuring Ribbon-Localized $\mathrm{Ca}^{2+}$ Responses}

To measure $\mathrm{Ca}^{2+}$ changes at individual ribbons, we drew regions of interest (ROIs) around each ribbon-associated hotspot, tightly delineating regions with clear and distinct $\mathrm{Ca}^{2+}$ increases. In experiments where we also included a fluorescent RIBEYE-binding peptide in the patch pipette to label ribbons (e.g., Figure $\mathbf{1} \mathbf{A}_{4}$ ), ROIs for $\mathrm{Ca}^{2+}$ hotspots were defined by outlining the region of peptide fluorescence in the same confocal plane.

The size of an ROI can influence $\mathrm{Ca}^{2+}$ signal amplitude. To examine the impact of ROI area, we used RIBEYE-binding peptide fluorescence to define the ribbon boundary and then 

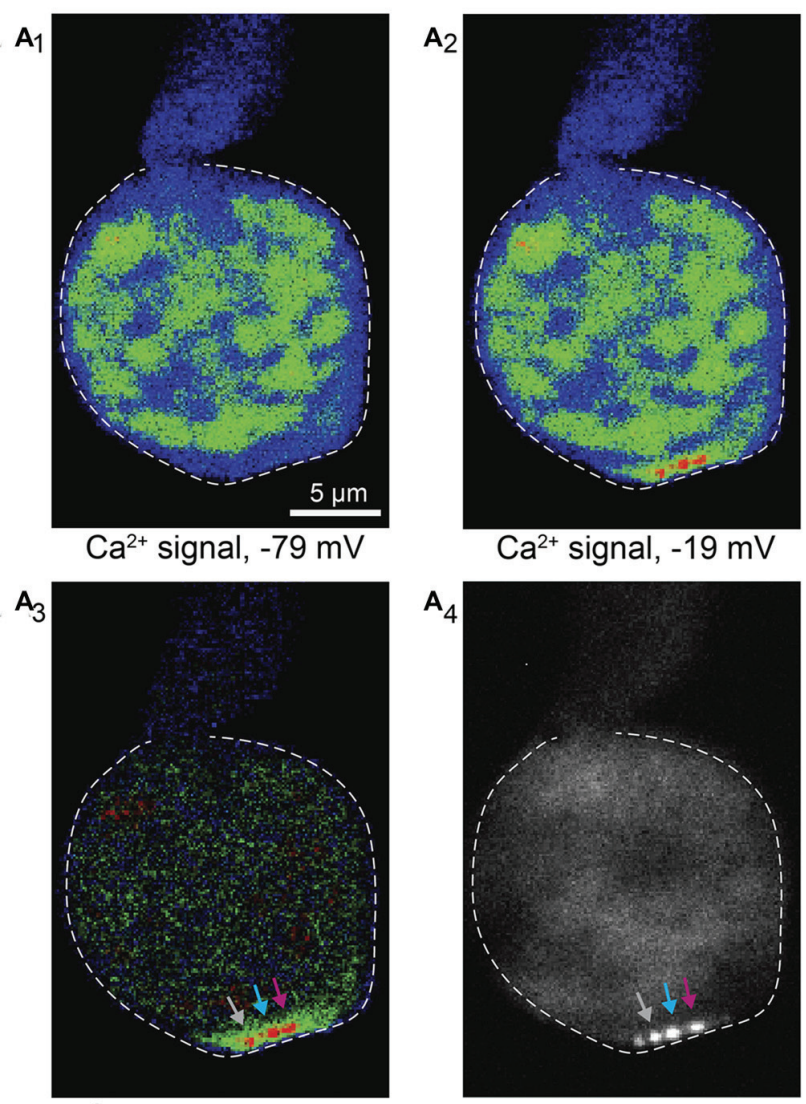

$\mathrm{Ca}^{2+}$ signals, subtracted

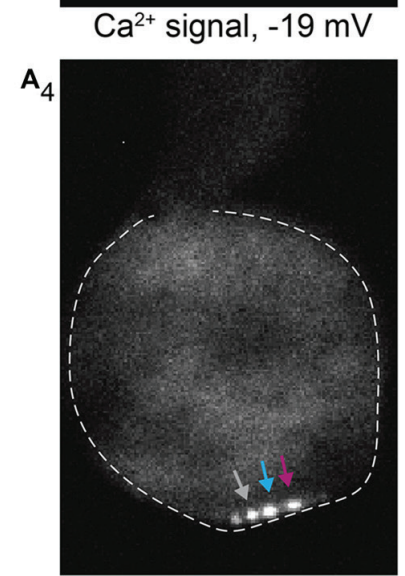

RIBEYE-binding peptide
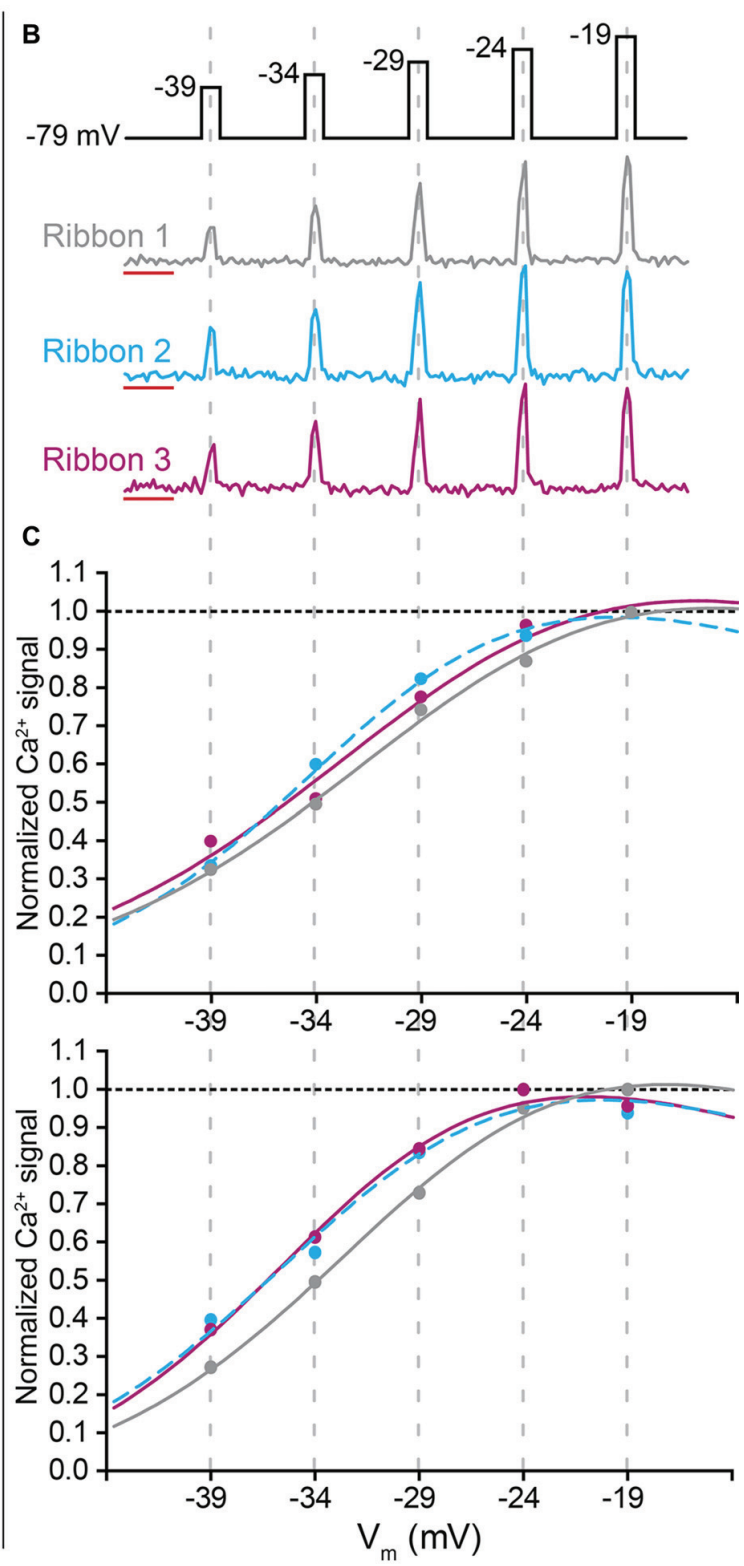

FIGURE 1 | Depolarizing steps result in areas of localized $\mathrm{Ca}^{2+}$ influx at cone ribbons. (A) Example of a cone loaded with the low-affinity $\mathrm{Ca}^{2+}$ indicator OGB-5N and TAMRA-conjugated RIBEYE-binding peptide. A series of depolarizing steps was delivered to the cell to stimulate $\mathrm{Ca}^{2+}$ influx (from $-79 \mathrm{mV}$ to test potentials ranging from $-39 \mathrm{mV}$ to $-19 \mathrm{mV}$ in $5 \mathrm{mV}$ increments, $175 \mathrm{~ms}$ apiece). Panel $\left(\mathbf{A}_{\mathbf{1}}\right)$ shows the pseudocolor fluorescence image (single $57 \mathrm{~ms}$ frame) of OGB-5N fluorescence in a cone prior to stimulation. Panel $\left(\mathbf{A}_{2}\right)$ shows an image from the same cone during a depolarizing step to $-19 \mathrm{mV}$. Panel $\left(\mathbf{A}_{3}\right)$ shows the difference image obtained by subtracting the control image in $\left(\mathbf{A}_{\mathbf{1}}\right)$ from the test image in $\left(\mathbf{A}_{\mathbf{2}}\right)$, revealing three distinct sites of $\mathrm{Ca}^{2+}$ influx in the terminal (arrows). In this cone, TAMRA-conjugated RIBEYE-binding peptide was also delivered by patch pipette, and the labeled ribbons observed at the same confocal plane are shown in panel $\left(\mathbf{A}_{4}\right)$. (B) The cone voltage stimulation protocol and $\mathrm{Ca}^{2+}$ responses of the three ribbons shown in Panel (A). Traces show the fractional change in fluorescence over baseline $(\Delta \mathrm{F} / \mathrm{F})$. The region used to measure baseline fluorescence during the first $1.3 \mathrm{~s}$ is shown by the red lines. The graphs show $\Delta \mathrm{F} / \mathrm{F}$ measured in the three ribbons simultaneously during a single trial of the voltage stimulus protocol. (C) Data from two separate trials in this same cone showing peak $\Delta F / F$ values for each depolarizing stimulus plotted against test step potential after normalizing to the ribbon's maximum $\Delta \mathrm{F} / \mathrm{F}$ within the trial. The voltage dependence was determined by fitting these data with a Boltzmann function adjusted for $\mathrm{Ca}^{2+}$ driving force (lines). Best fit $\mathrm{V}_{50}$ and slope factor values for trial 1: ribbon 1, $-28.94 \mathrm{mV}(95 \%$ confidence interval: -32.25 to $-17.56 \mathrm{mV}), 7.145$; ribbon 2, $-32.61 \mathrm{mV}(-5.03$ to -30.20$), 5.616$; ribbon $3,-29.91 \mathrm{mV}(-42.25$ to -17.562$), 7.214$. Best fit values for trial 2: ribbon 1, $-30.46 \mathrm{mV}(-33.75$ to $-27.17 \mathrm{mV}), 6.240$; ribbon 2, $-33.61 \mathrm{mV}(-40.36$ to -26.86$), 6.028$; ribbon $3-33.93 \mathrm{mV}(-37.07$ to -30.79$), 5.621$.

compared the amplitude of depolarization-evoked $\mathrm{Ca}^{2+}$ changes $(\Delta \mathrm{F} / \mathrm{F})$ as we varied $\mathrm{ROI}$ size around the ribbon (Figure $\mathbf{2 A})$. As illustrated in Figure 2B, $\Delta \mathrm{F} / \mathrm{F}$ of $\mathrm{Ca}^{2+}$ responses decreased as
ROI area was expanded to incorporate weakly responsive regions beyond the ribbon margins (blue border in Figure 2A). Using a very small ROI $(4 \times 4$ pixels, $\sim 0.4 \times 0.4 \mu \mathrm{m}$, green border in 


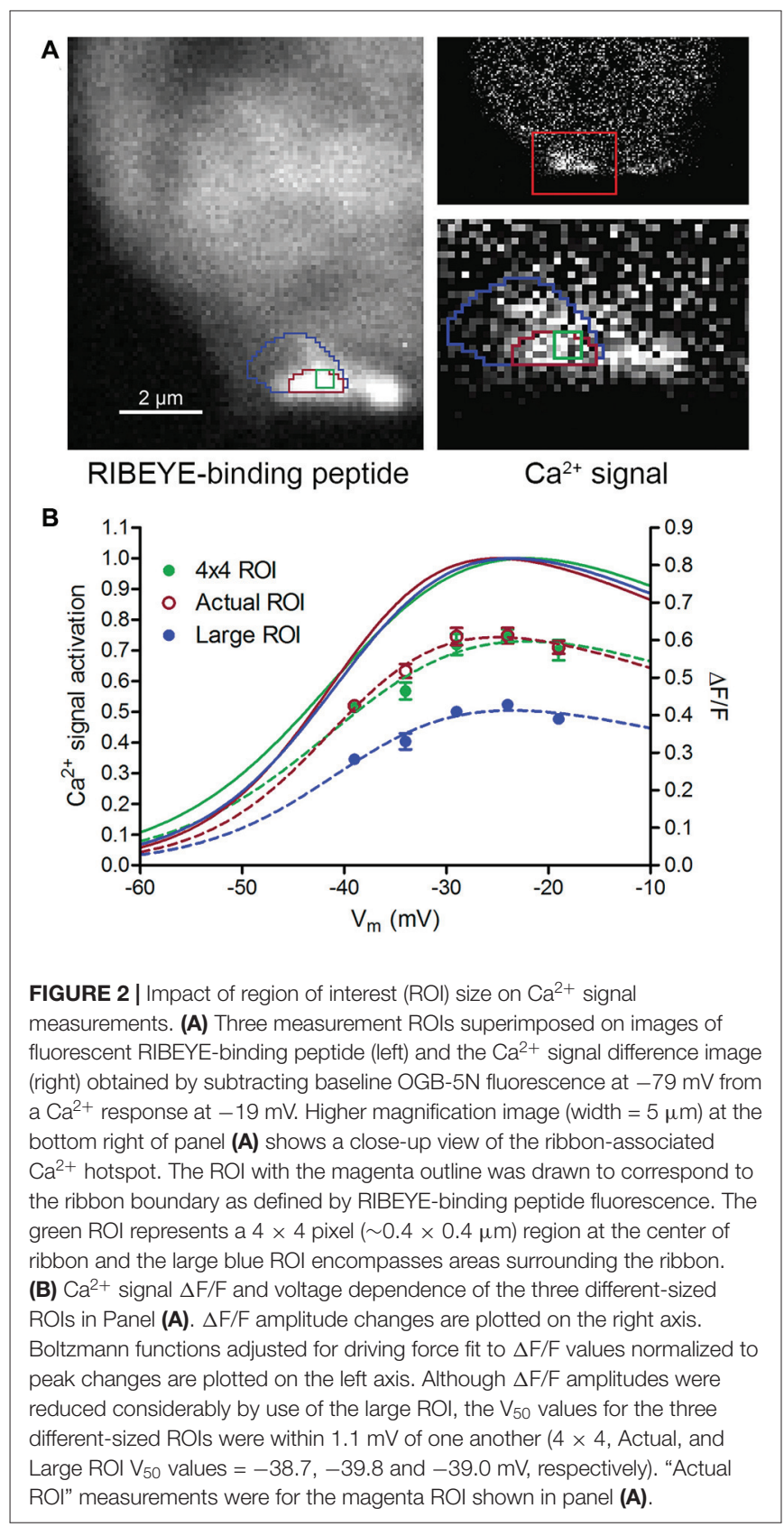

Figure 2A) centered within the $\mathrm{Ca}^{2+}$ hotspot did not increase the amplitude of $\Delta \mathrm{F} / \mathrm{F}$ values beyond those measured with an ROI that delineated the entire ribbon (e.g., magenta border in Figure 2A). Use of such small ROIs placed in sub-regions did, however, increase measurement noise, so we integrated $\mathrm{Ca}^{2+}$ signals within the entire ribbon area to measure ribbon $\mathrm{Ca}^{2+}$ responses.

While changes in ROI size clearly affected $\Delta \mathrm{F} / \mathrm{F}$ amplitude, the normalized $\mathrm{Ca}^{2+}$ responses in Figure $2 \mathrm{~B}$ show that the voltage dependence of $\mathrm{Ca}^{2+}$ signals was nearly identical for the three different-sized ROIs shown in Figure 2A. This is because voltage-dependent changes in $\mathrm{Ca}^{2+}$ fluorescence are strongly dominated by the signal at the center of the hotspot and so including additional weakly responsive regions had little impact. Similar comparisons performed in three other cones also showed that increasing ROI size diminished $\Delta \mathrm{F} / \mathrm{F}$ amplitude but did not appreciably alter $\mathrm{V}_{50}$ values for $\mathrm{Ca}^{2+}$ signals. Therefore, while differences in ROI size contributed to $\Delta \mathrm{F} / \mathrm{F}$ amplitude variability in our measurements, they did not appear to significantly alter $V_{50}$ values.

We also examined the impact of confocal plane on measurements of ribbon $\mathrm{Ca}^{2+}$ signals. In experiments where we introduced fluorescent RIBEYE peptide through the patch pipette, we began $\mathrm{Ca}^{2+}$ measurements in the minutes before sufficient RIBEYE peptide had reached the synaptic terminal to produce strong ribbon labeling. Therefore, we typically selected the $\mathrm{Ca}^{2+}$ measurement plane by iterative positioning of the objective's $z$-axis and application of depolarizing steps to locate discrete $\mathrm{Ca}^{2+}$ hotspots. To assess the accuracy of identifying ribbon-localized $\mathrm{Ca}^{2+}$ hotspots in this way, we compared the plane selected for $\mathrm{Ca}^{2+}$ measurements to the plane of the associated ribbon determined from a confocal $\mathrm{z}$-stack of fluorescent RIBEYE peptide labeling (28 ribbons in 11 cones). $\mathrm{Ca}^{2+}$ measurements and z-stack images of RIBEYE fluorescence were typically acquired a few minutes apart from one another and small movements of the recording pipette or tissue during that time may have introduced additional displacements between the two measurements. Nonetheless, $\mathrm{Ca}^{2+}$ measurement planes and the brightest RIBEYE fluorescence planes differed by only $0.38 \pm 0.60 \mu \mathrm{m}$ (Figure 3A). When we examined the $z$-axis position of single fluorescent beads, we found that the beads imaged with 488 excitation/525 nm emission appeared to be $0.070 \pm 0.066 \mu \mathrm{m}$ ( $p=0.009$, paired $t$-test; $n=10$ beads $)$ above the same beads imaged with $568 \mathrm{~nm}$ excitation/600 nm emission. Taking these optical differences into account reduces the difference between measured planes to $0.31 \pm 0.60 \mu \mathrm{m}$. This is less than the axial resolution of the $60 \times, 1.0 \mathrm{NA}$ objective measured at $525 \mathrm{~nm}$ emission $(1.45 \mu \mathrm{m})$. This shows good agreement between planes chosen for $\mathrm{Ca}^{2+}$ signal measurements and ribbon planes identified by RIBEYE peptide labeling.

These results show that $\mathrm{Ca}^{2+}$ signals were measured at or very near the actual ribbon plane, but we also considered how imperfect positioning of the focal plane of measurement might impact a ribbon's calculated $\mathrm{V}_{50}$ value. To do so, we measured $\mathrm{Ca}^{2+}$ responses of a ribbon at one plane and then moved the objective up or down to make a second measurement. Fluorescent peptide was not included in these experiments and so we defined the ribbon plane post hoc as the plane showing the strongest $\mathrm{Ca}^{2+}$ response (largest $\Delta \mathrm{F} / \mathrm{F})$. As illustrated in Figure 3B, movements of $\pm 1.1 \mu \mathrm{m}$ away from the plane of the ribbon caused a statistically insignificant $\mathrm{V}_{50}$ shift that averaged $+0.7 \pm 2.9 \mathrm{mV}(p=0.23)$ for 25 ribbons in 12 cones. A $\pm 2.3 \mu \mathrm{m}$ change in focal plane caused a larger, statistically significant positive shift in $\mathrm{V}_{50}$ of $+1.6 \pm 2.5 \mathrm{mV}(p=0.04)$. The ability of $\pm 2.3 \mu \mathrm{m}$ changes in focal plane to produce significant positive shifts in $\mathrm{V}_{50}$ values is likely a consequence of $\mathrm{Ca}^{2+}$ buffering and dye properties, such that greater $\mathrm{Ca}^{2+}$ influx is required to 


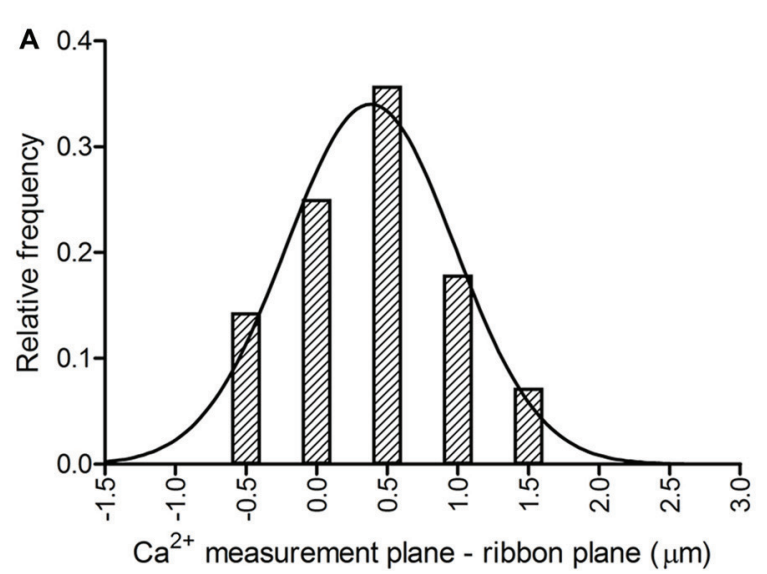

B

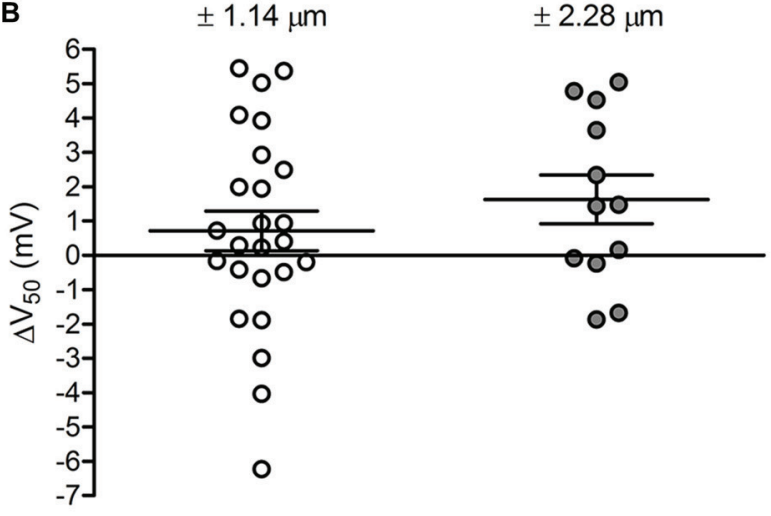

FIGURE 3 | Assessing potential effects of focal plane placement on $\mathrm{Ca}^{2+}$ measurements. (A) Frequency distribution of the distance between the focal plane at which a ribbon's $\mathrm{Ca}^{2+}$ signal was measured and the plane at which the peak fluorescence of TAMRA-conjugated RIBEYE-binding peptide was observed in a confocal z-stack acquired the end of the recording (Gaussian mean $=0.38 \mu \mathrm{m}, \mathrm{SD}=0.60 \mu \mathrm{m}$; fit $R^{2}=0.96 ; n=28$ ribbons in 11 cones). (B) Effect of focal plane position on $V_{50}$ values. Moving the focal plane of $\mathrm{Ca}^{2+}$ measurement away from the ribbon plane $\pm 1.14 \mu \mathrm{m}$ shifted $V_{50}$ values positively by $+0.7 \pm 2.9 \mathrm{mV}(p=0.23$, paired $t$-test; $n=25$ ribbons in 12 cones). Moving the plane $\pm 2.28 \mu \mathrm{m}$ shifted $V_{50}$ values by $+1.6 \pm 2.5 \mathrm{mV}$ $(p=0.04$, paired $t$-test; $n=12$ ribbons in 9 cones). Data are displayed as mean \pm SEM.

attain levels that can be accurately detected with the low-affinity $\mathrm{Ca}^{2+}$ dye.

Although large errors in focal plane placement can produce significant $\mathrm{V}_{50}$ shifts, these results suggest that iterative $z$-axis positioning between $\mathrm{Ca}^{2+}$ imaging trials to select the best focal plane resulted in $\sim 95 \%$ of $\mathrm{Ca}^{2+}$ measurements being performed in a range spanning $1.2 \mu \mathrm{m}$ about the ribbon plane. Trial-to-trial differences between $\mathrm{V}_{50}$ values of $\mathrm{Ca}^{2+}$ measurements made at different $( \pm 1.1 \mu \mathrm{m})$ focal planes did not differ significantly from trial-to-trial differences between $V_{50}$ values obtained at the same focal plane ( $p=0.44, t$-test; $n=25$ and 20 ribbons, respectively). This further indicates that focal plane selection had little or no impact on measurement variability. Taken together, these results show that $\mathrm{Ca}^{2+}$ signals were measured at focal planes that lay within the axial resolution limit to the true ribbon planes and that small differences among ribbon measurement focal planes did not introduce significant additional variability to $V_{50}$ values.

Because both focal plane and ROI size can influence the amplitude of $\Delta \mathrm{F} / \mathrm{F}$ measurements in ribbons, we focused most of our analysis on ribbon-to-ribbon differences in voltage dependence. However, there were also genuine differences in $\mathrm{Ca}^{2+}$ influx magnitude among ribbons. For example, while peak $\Delta \mathrm{F} / \mathrm{F}$ values averaged $0.76 \pm 0.77$, one ribbon showed a peak $\Delta F / F$ value of 3.95 , more than $4 \mathrm{SD}$ above the average. This large $\mathrm{Ca}^{2+}$ increase was not due to use of a particularly small ROI nor can it be explained by focal plane positioning.

In experiments where we labeled ribbons with a fluorescent RIBEYE-binding peptide, we measured the length of the ribbon in the $\mathrm{x}-\mathrm{y}$ plane by determining the distance between two points along the ribbon's longest axis where fluorescence intensity had declined by $50 \%$ (full width at half maximum, FWHM). Measurements of ribbon length scale roughly with total ribbon size since the base of the ribbon is longer and varies more than the other two ribbon dimensions. Cone ribbons are $35-60 \mathrm{~nm}$ thick and extend $<350 \mathrm{~nm}$ into the cytoplasm, but the length of a ribbon along its base can be well over $1 \mu \mathrm{m}$ (Pierantoni and McCann, 1984; Pang et al., 2008). Fluorescentlylabeled ribbons measured along their longest axis averaged $1.89 \pm 0.87 \mu \mathrm{m}(n=26)$. The optical point spread function showed a FWHM of $0.45 \mu \mathrm{m}$. Therefore, after consideration of optical blurring, fluorescent measurements of ribbon length are consistent with ultrastructural measurements in light-adapted turtle cones, in which ribbon length averaged $1.2 \pm 0.6 \mu \mathrm{m}$ (Pierantoni and McCann, 1984). This supports the idea that individual $\mathrm{Ca}^{2+}$ hot spots generally arose from activity at individual ribbons.

The length of a ribbon along its base determines the number of vesicles that can be tethered at the plasma membrane and thus determines the size of the readily releasable pool of vesicles (Pang et al., 2008; Bartoletti et al., 2010). We predicted that the number of $\mathrm{Ca}^{2+}$ channels clustered beneath the base of each ribbon would also be correlated with the length of the ribbon. We therefore compared the length of each ribbon to the FWHM of the associated $\mathrm{Ca}^{2+}$ signal. As predicted, we found a strong linear correlation between ribbon size and the spatial extent of the associated $\mathrm{Ca}^{2+}$ signal (Figure 4A, $\left.R^{2}=0.75\right)$.

In cochlear inner hair cells, the maximum amplitude of depolarization-evoked $\mathrm{Ca}^{2+}$ signals increased with increasing ribbon size (Frank et al., 2009; Ohn et al., 2016). We found no correlation between ribbon size and peak $\Delta F / F$ values attained in the associated $\mathrm{Ca}^{2+}$ hotspot (Figure $4 \mathrm{~B}, R^{2}=0.02$ ) and the slope of the regression line did not differ significantly from zero ( $F$-test, $p=0.48)$. The finding that $\mathrm{Ca}^{2+}$ signals are strongly correlated in spatial extent, but not peak amplitude, with ribbon size suggests that the number of $\mathrm{Ca}^{2+}$ channels generally scales with ribbon size.

The voltage-dependent activation of L-type $\mathrm{I}_{\mathrm{Ca}}$ can be altered changes in extracellular pH (Iijima et al., 1986; Krafte and Kass, 1988; Barnes et al., 1993). To assess our ability to accurately measure small changes in $\mathrm{V}_{50}$ from ribbon-associated changes 

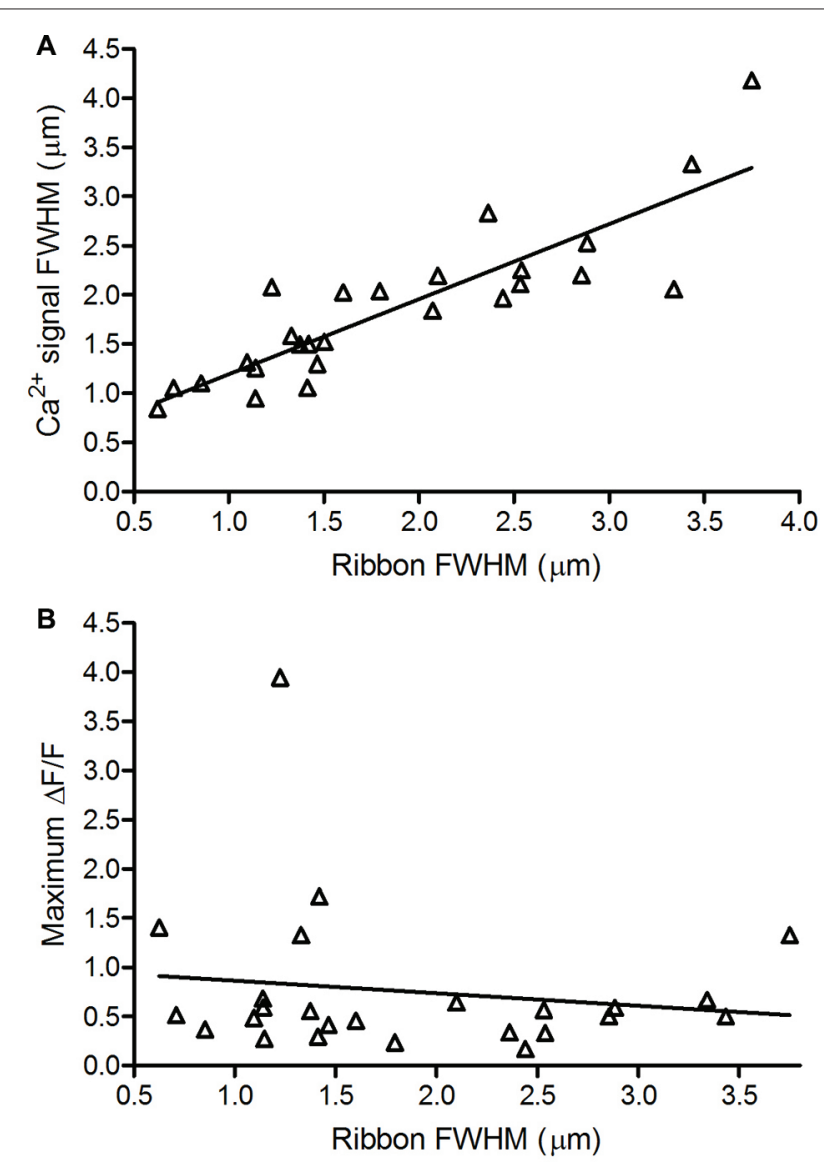

FIGURE 4 | Ribbon size is correlated with $\mathrm{Ca}^{2+}$ domain size but not maximal $\mathrm{Ca}^{2+}$ response amplitude. (A) Spatial extent of $\mathrm{Ca}^{2+}$ signals $(1.87 \pm 0.77 \mu \mathrm{m}$, $n=26$; measured as the FWHM of the peak depolarization-evoked OGB-5N fluorescence change) vs. size of the associated ribbon $\left(R^{2}=0.75 ; p<0.0001\right.$, $F$-test for non-zero slope). (B) Maximum $\Delta F / F$ amplitude of $\mathrm{Ca}^{2+}$ signals vs. size of the associated ribbon. Maximum $\Delta F / F$ amplitude of $\mathrm{Ca}^{2+}$ signals averaged $0.76 \pm 0.77(n=25)$. Ribbon size is represented by the full-width half maximum (FWHM) of the TAMRA-conjugated RIBEYE-binding peptide fluorescence measured along its longest axis in its brightest confocal plane (1.86 $\pm 0.90 \mu \mathrm{m}, n=25 ; R^{2}=0.02 ; p=0.48, F$-test for non-zero slope).

in $\mathrm{Ca}^{2+}$, we altered the $\mathrm{pH}$ of the extracellular saline from 7.8 (control) to 7.6 to induce small changes in voltage dependence of $\mathrm{I}_{\mathrm{Ca}}$ activation. Consistent with earlier measurements of the effect of $\mathrm{pH}$ on salamander cone $\mathrm{I}_{\mathrm{Ca}}$ (Barnes and Bui, 1991; Barnes et al., 1993), lowering $\mathrm{pH}$ by 0.2 units shifted $\mathrm{V}_{50}$ values of $\mathrm{I}_{\mathrm{Ca}}$ in cones by $+3.2 \mathrm{mV}$ (Figure 5, $p=0.03$ ). This 0.2 unit $\mathrm{pH}$ change caused a readily detectable and significant shift in the $V_{50}$ of $\mathrm{Ca}^{2+}$ signals measured optically at individual ribbons in the same cones that averaged $+3.3 \mathrm{mV}$ (Figure 5, $p=0.03$ ). These small, reproducible changes in $\mathrm{V}_{50}$ induced by altering extracellular $\mathrm{pH}$ confirmed that small differences in $\mathrm{Ca}^{2+}$ signal voltage dependence could be reliably detected at individual ribbons in our experiments.

\section{Cone-to-Cone $\mathrm{I}_{\mathbf{C a}} \mathbf{V}_{\mathbf{5 0}}$ Variability}

Cone-to-cone differences in the voltage dependence of $\mathrm{I}_{\mathrm{Ca}}$ activation could be a source of post-synaptic variability in

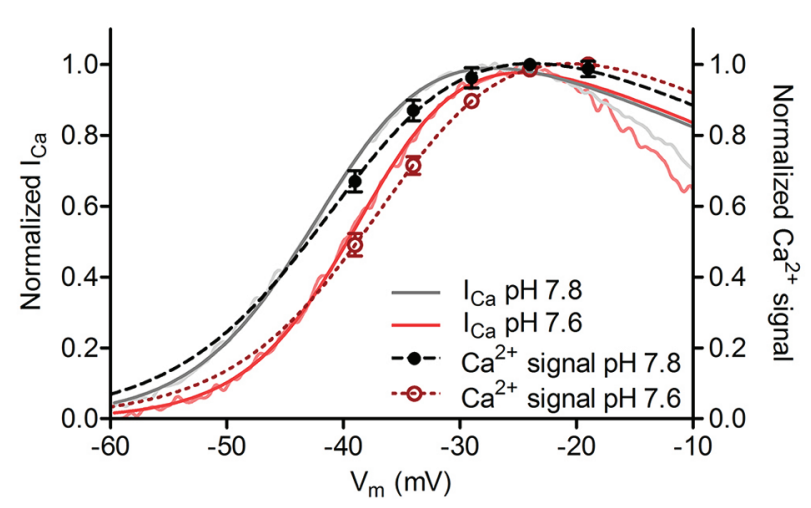

FIGURE 5 | Small changes in voltage dependence of $\mathrm{Ca}^{2+}$ influx could be accurately detected. Cone $\mathrm{I}_{\mathrm{Ca}}$ and ribbon $\mathrm{Ca}^{2+}$ signals plotted against test potential at extracellular $\mathrm{pH}$ values of 7.8 and 7.6. Changing the $\mathrm{pH}$ of extracellular saline from 7.8 (control condition) to 7.6 produced a positive shift in voltage dependence of ribbon $\mathrm{Ca}^{2+}$ responses $\left(\mathrm{V}_{50}\right.$ shift $=+3.3 \mathrm{mV}$, dashed lines) and whole cell $\mathrm{I}_{\mathrm{Ca}}\left(\mathrm{V}_{50}\right.$ shift $=+3.2 \mathrm{mV}$, solid lines; $p=0.03$ for both comparisons, paired $t$-test; $n=8$ ribbons in 7 cones). Normalized $\mathrm{I}_{\mathrm{Ca}}$ traces (pink and light gray) were low-pass filtered at $200 \mathrm{~Hz}$ to facilitate visual comparison.

bipolar cells as well as a source of variability in $\mathrm{V}_{50}$ values when comparing ribbons in different cones. We therefore examined the variability of $V_{50}$ values calculated from cone $\mathrm{I}_{\mathrm{Ca}}$ activation curves measured electrophysiologically. Technical variability in measurements of $\mathrm{I}_{\mathrm{Ca}}$ in different cones could arise from differences in series resistance $\left(\mathrm{R}_{\mathrm{ser}}\right)$ during whole-cell patch clamp recordings. To minimize this, we employed an amplifier (Alembic VE-2, Alembic Instruments) with circuitry that allows complete and stable compensation of $\mathrm{R}_{\text {ser }}$ (Sherman et al., 1999). We measured cone $\mathrm{I}_{\mathrm{Ca}}$ using a ramp voltage protocol ( -99 to $+51 \mathrm{mV}, 0.5 \mathrm{mV} / \mathrm{ms}$ ) with $\mathrm{P} / 8$ subtraction of passive membrane properties and then fit the normalized $\mathrm{I}_{\mathrm{Ca}}$ curve with a Boltzmann function adjusted for driving force. An example of $\mathrm{I}_{\mathrm{Ca}}$ analyzed in this way is shown in Figure 6A, while Figure 6B shows overlaid Boltzmann fits of $\mathrm{I}_{\mathrm{Ca}}$ from 21 cones. Even after compensating for $\mathrm{R}_{\mathrm{ser}}$, we found modest differences in the voltage dependence of $\mathrm{I}_{\mathrm{Ca}}$ from cone to cone, with an average $\mathrm{V}_{50}$ of $-38.1 \pm 3.05 \mathrm{mV}$ (variance $=9.28 \mathrm{mV}^{2}$, $n=28$ cones) and slope factor of $4.90 \pm 1.34$. The peak amplitude also differed among cones, averaging $163.6 \pm 41.6 \mathrm{pA}$ $(n=28)$.

We analyzed trial-to-trial variability of $\mathrm{V}_{50}$ values obtained from repeated $\mathrm{I}_{\mathrm{Ca}}$ measurements in the same cone, which produced an average variance of $1.0 \mathrm{mV}^{2}(\mathrm{SD}=1.0 \mathrm{mV})$. The Alembic amplifier circuitry allows near complete compensation for $\mathrm{R}_{\text {ser }}$, but the Clampex membrane test evaluator suggested a small residual $\mathrm{R}_{\text {ser }}$ averaging $2.1 \pm 0.58 \mathrm{M} \Omega(n=36)$. In 14 of the 28 cones used for ribbon analysis, we calculated the voltage error that would be introduced by $\mathrm{R}_{\text {ser }}$ after accounting for both the steady holding current and the magnitude of the inward $\mathrm{I}_{\mathrm{Ca}}$ at its activation midpoint. The voltage error in these recordings caused by residual, uncompensated $R_{\text {ser }}$ averaged $0.54 \pm 0.19 \mathrm{mV}$, indicating that the true $V_{50}$ for the cones in our analysis is slightly more negative than the value reported above. Additionally, this 

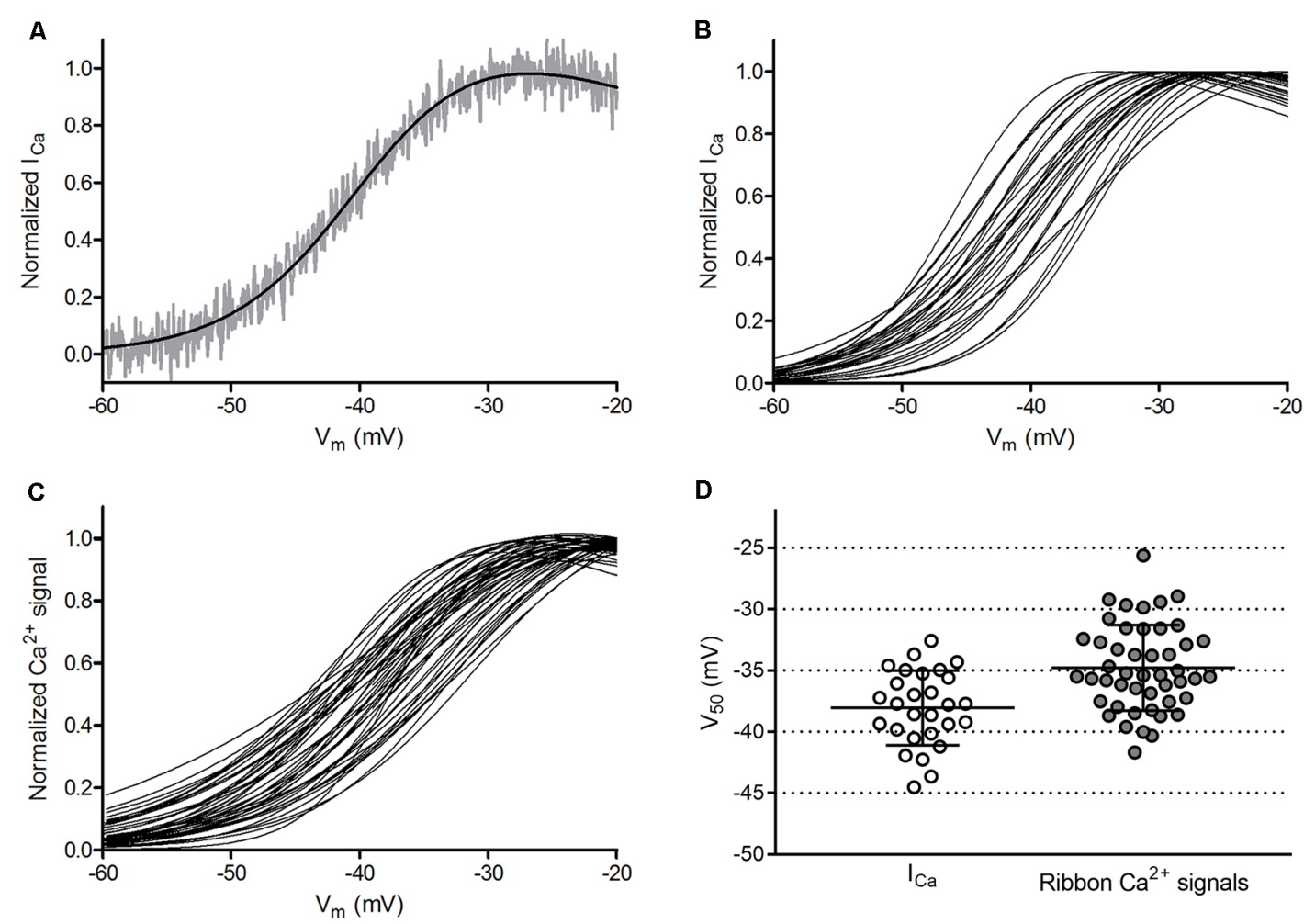

FIGURE 6 | Ribbon-to-ribbon $\mathrm{Ca}^{2+}$ activation is more variable than cone-to-cone $\mathrm{I}_{\mathrm{Ca}}$ activation. (A) $\mathrm{I}_{\mathrm{Ca}}$ in one cone with $\mathrm{R}_{\text {ser }}$ completely compensated. $\mathrm{I}_{\mathrm{Ca}}$ was normalized to its peak value and plotted against the cone holding potential during the voltage ramp protocol (gray trace). A Boltzmann function adjusted for driving force was fit to these data (black line, $V_{50}=-39.3$, slope factor $=4.88$ ). Inward currents are plotted upward to compare more easily with $\mathrm{Ca}^{2+}$ signal measurements. For this illustration, currents were digitally corrected for the passive membrane resistance measured in the range from $-85 \mathrm{mV}$ to $-70 \mathrm{mV}$. (B) Overlaid Boltzmann function fits to normalized $\mathrm{I}_{\mathrm{Ca}}$ from the 28 cones in which ribbon $\mathrm{Ca}^{2+}$ signals in Panel (C) were measured. (C) Overlaid Boltzmann function fits to ribbon-associated $\mathrm{Ca}^{2+}$ signals of 47 ribbons in the 28 cones shown in Panel (B). Ribbons were analyzed as illustrated in Figure 1. (D) Distribution of $V_{50}$ values calculated from Boltzmann function fits to $\mathrm{I}_{\mathrm{Ca}}$ (average $=-38.1 \pm 3.0 \mathrm{mV}$ ) and optical ribbon $\mathrm{Ca}^{2+}$ measurements made with OGB-5N (average $=-34.8 \pm 3.5 \mathrm{mV}$ ). Bars show the mean \pm SD.

analysis shows that variability in residual $\mathrm{R}_{\text {ser }}$ among cones had a negligible impact on variance $\left(0.04 \mathrm{mV}^{2}\right)$ in $\mathrm{I}_{\mathrm{Ca}} \mathrm{V}_{50}$ values among cones.

Assuming a cone should have an unchanging $\mathrm{I}_{\mathrm{Ca}}$ voltage dependence, the genuine biological variability for $\mathrm{I}_{\mathrm{Ca}} \mathrm{V}_{50}$ among cones would have a SD of $2.9 \mathrm{mV}$ (variance $=8.24 \mathrm{mV}^{2}$ after subtracting trial-to-trial and $\mathrm{R}_{\text {ser }}$ variance). Our recordings were largely performed in large single cones but also included some small single cones and double cones (Mariani, 1986; Sherry et al., 1998). $V_{50}$ values for $I_{C a}$ showed a single Gaussian distribution (Figure 6), suggesting considerable overlap of voltage dependence among subtypes. Furthermore, in a separate set of experiments using the same ramp protocol to measure $\mathrm{I}_{\mathrm{Ca}}$, we found no significant differences in $\mathrm{V}_{50}$ values among these three cone subtypes ( $p=0.56$, analyses of variance (ANOVA); $n=5$ small single cones, 6 large single cones, 6 principal members of double cones). The traditional view is that the membrane potential for cones in darkness $(-40 \mathrm{mV})$ rests near the foot of the activation curve for $\mathrm{I}_{\mathrm{Ca}}$ (Barnes and Kelly, 2002), but our results indicate that $\mathrm{I}_{\mathrm{Ca}}$ would attain approximately half-maximal activation in darkness. As discussed later, small cone-to-cone differences in resting membrane potential and $\mathrm{I}_{\mathrm{Ca}} \mathrm{V}_{50}$ values can produce functionally significant differences in $\mathrm{Ca}^{2+}$ influx and synaptic output.

\section{$\mathrm{Ca}^{2+}$ Signals at Cone Ribbon Sites Exhibited Small Differences in Voltage Activation}

Cone synaptic terminals contain a dozen or more synaptic ribbons that are each potentially capable of providing distinct output channels to second-order horizontal and bipolar cells. To determine whether these channels all transmit signals with equal voltage dependence, we examined the $\mathrm{Ca}^{2+}$ activation profiles of many cone ribbon sites, including multiple ribbons from some cones. Figure $6 \mathrm{C}$ shows an overlay of the $\mathrm{Ca}^{2+}$ activation curves from 47 ribbons in the 28 cones shown in Figure 6B. The $\mathrm{V}_{50}$ values for cone ribbon $\mathrm{Ca}^{2+}$ signals averaged $-34.8 \pm 3.49 \mathrm{mV}$. Slope factors for the Boltzmann fit averaged $6.76 \pm 1.73$. This differed significantly $(p<0.0001)$ from slope values for $\mathrm{I}_{\mathrm{Ca}}$ due to the non-linear binding properties of the $\mathrm{Ca}^{2+}$ dye. The distributions of $\mathrm{V}_{50}$ values calculated for cone $\mathrm{I}_{\mathrm{Ca}}$ (Figure 6B) and ribbon $\mathrm{Ca}^{2+}$ signals within these cones (Figure 6C) are both plotted in Figure 6D, and 
both exhibited a normal distribution $(p=0.71$ and 0.57 , respectively, D’Agostino and Pearson omnibus normality test). Even though multiple ribbons were often measured in a single cone, $\mathrm{V}_{50}$ values of ribbon $\mathrm{Ca}^{2+}$ signals showed slightly greater variability than $\mathrm{V}_{50}$ values of cone $\mathrm{I}_{\mathrm{Ca}}$. Thus, the voltage dependence of ribbon $\mathrm{Ca}^{2+}$ signals was more variable than would be expected if all ribbons within a cone operated identically.

The $\mathrm{V}_{50}$ values calculated from ribbon $\mathrm{Ca}^{2+}$ influx in cones were $3.3 \mathrm{mV}$ more positive than $\mathrm{V}_{50}$ values determined from $\mathrm{I}_{\mathrm{Ca}}$ (Figure 6D). We hypothesized that this rightward shift in activation was due to the low sensitivity of the low affinity $\mathrm{Ca}^{2+}$ indicator (OGB-5N, $K_{\mathrm{d}}=20 \mu \mathrm{M}$ ), such that small $\mathrm{Ca}^{2+}$ influxes evoked by weak depolarization lie below the dye's linear response range. To test this idea, we repeated our experiments using a slightly higher-affinity $\mathrm{Ca}^{2+}$ indicator, OGB-6F $\left(K_{\mathrm{d}}=3 \mu \mathrm{M}\right)$, and expanded the test step series to include weaker steps to -49 and $-44 \mathrm{mV}$. In support of our hypothesis, the difference in $\mathrm{V}_{50}$ between $\mathrm{Ca}^{2+}$ signals and $\mathrm{I}_{\mathrm{Ca}}$ was reduced to $2.3 \mathrm{mV}$ when using OGB-6F ( $n=25$ ribbons in 11 cones). However, $\mathrm{Ca}^{2+}$ hotspots were less tightly constrained with this higher-affinity dye, so we used OGB-5N for experiments examining ribbon-toribbon differences in $\mathrm{Ca}^{2+}$ signals.

\section{Estimating Genuine Ribbon-to-Ribbon Variability}

To analyze how much ribbons truly differ in voltage dependence from one another, we evaluated sources of technical and biological variability in our measurements. Variability in $V_{50}$ values for ribbon-associated $\mathrm{Ca}^{2+}$ signals $(\mathrm{SD}=3.49 \mathrm{mV}$, variance $=12.18 \mathrm{mV}^{2}$, see Figure 6) could potentially arise from four sources: (1) technical variability in electrophysiological control of cone $\mathrm{I}_{\mathrm{Ca}}$; (2) biological cone-to-cone variability in $\mathrm{I}_{\mathrm{Ca}}$ activation; (3) technical variability in optical measurements of $\mathrm{Ca}^{2+}$ signals; and (4) biological ribbon-to-ribbon variability in ribbon-associated $\mathrm{Ca}^{2+}$ signals. The combined impact of sources 1 and 2 (technical and biological variability of $\mathrm{I}_{\mathrm{Ca}}$ among cones) was captured by measurements of variability among whole cell $\mathrm{I}_{\mathrm{Ca}}$ in different cones $\left(\mathrm{V}_{50} \mathrm{SD}=3.05 \mathrm{mV}\right.$, variance $=9.28 \mathrm{mV}^{2}$, $n=28$ cones, see Figure 6D).

We assessed the amount of variance in $\mathrm{Ca}^{2+}$ signals among ribbons that can be explained by the variance in whole cell $\mathrm{I}_{\mathrm{Ca}}$ among cones by examining the correlation between $V_{50}$ values of cone $I_{C a}$ and $V_{50}$ values of the ribbons measured in the same cones. We expected to find that much of the ribbon-to-ribbon variability would be explained by cone-tocone variability in whole cell $\mathrm{I}_{\mathrm{Ca}}$. However, we instead found that $\mathrm{V}_{50}$ values for ribbon $\mathrm{Ca}^{2+}$ signals were only weakly correlated with $\mathrm{I}_{\mathrm{Ca}} \mathrm{V}_{50}$ values from the cones in which they were measured $\left(R^{2}=0.105\right.$, slope $=0.39 \pm 0.17$ [SEM]; $p=0.026)$. To avoid weighting some cells more heavily than others, we repeated this comparison after choosing a single ribbon from each cell. Selecting a single ribbon from each cone to minimize the difference between ribbon $V_{50}$ and $I_{C a} V_{50}$ (and thus maximize the correlation) improved the correlation to $R^{2}=0.228$ (gray circles in Figure 7A; slope $=0.52 \pm 0.19$ $[\mathrm{SEM}] ; p=0.01)$. Selecting the one ribbon from each cone

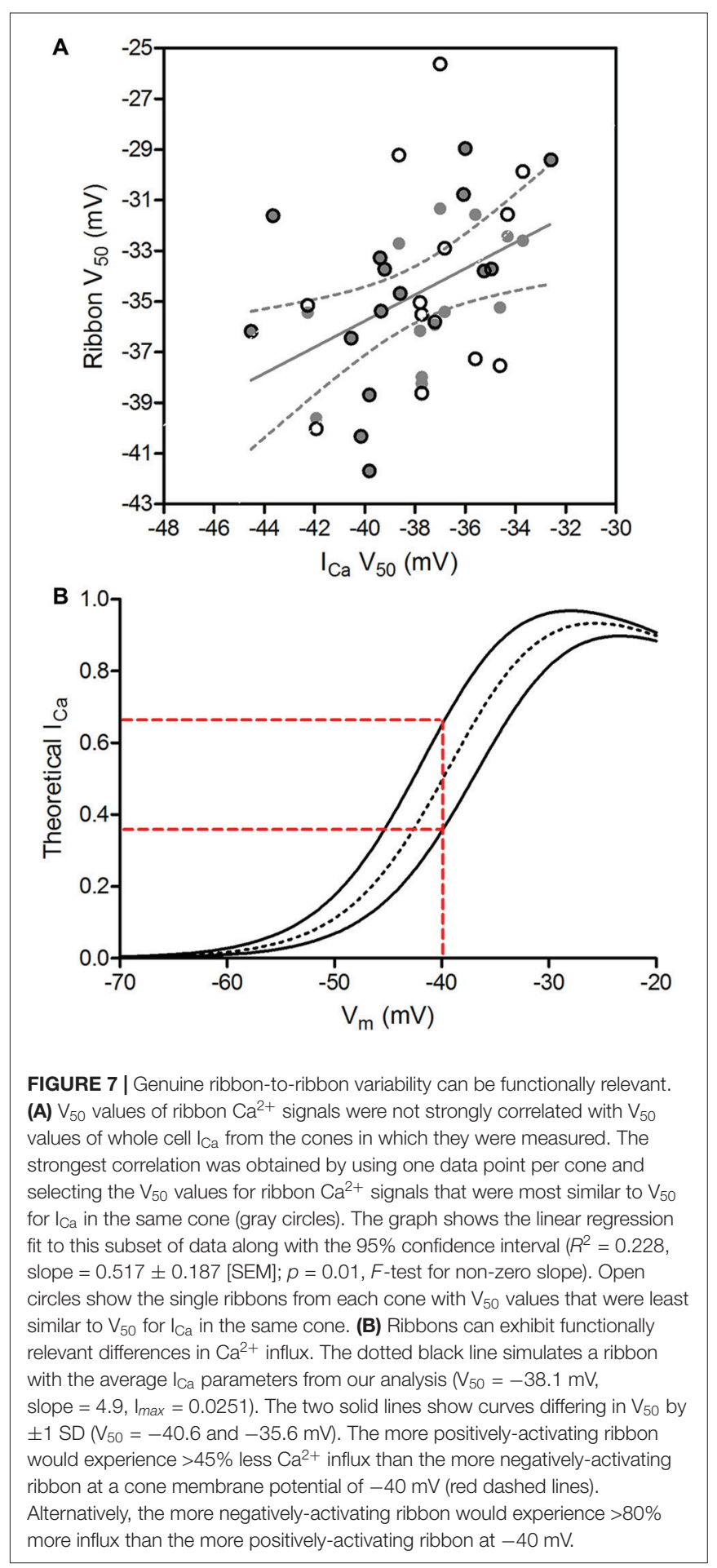

that maximized the difference between ribbon $\mathrm{V}_{50}$ and $\mathrm{I}_{\mathrm{Ca}}$ $\mathrm{V}_{50}$ also slightly improved the correlation (open circles in Figure 7A; $R^{2}=0.164$, slope $=0.52 \pm 0.23[\mathrm{SEM}] ; p=0.03$ ). These coefficients of determination indicate that $16.4 \%-22.8 \%$ of ribbon-to-ribbon variance can be attributed to variance in $\mathrm{I}_{\mathrm{Ca}}$ among cones. Thus, while the amount of variance among $\mathrm{V}_{50}$ values for ribbon $\mathrm{Ca}^{2+}$ measurements was not significantly greater than the variance among $\mathrm{V}_{50}$ values for $\mathrm{I}_{\mathrm{Ca}}$ ( $F$-test, 
$p=0.46$ ), the sources of variance in the two samples were largely independent.

We also assessed technical variability in optical measurements of $\mathrm{Ca}^{2+}$ signals (source 3). For each ribbon, we fit the voltagedependent $\Delta \mathrm{F} / \mathrm{F}$ profiles with a Boltzmann function adjusted for driving force. We acquired up to five replicate data points for each depolarizing step in some experiments, and when such replicates were available, we fit the entire sample as one. The standard errors for $\mathrm{V}_{50}$ values obtained by nonlinear regression fits to ribbon $\mathrm{Ca}^{2+}$ signals provide a way to quantify uncertainties in $\mathrm{V}_{50}$ contributed by optical $\mathrm{Ca}^{2+}$ measurement variability. From the standard errors of Boltzmann fits to $\mathrm{Ca}^{2+}$ imaging data, we found that measurement uncertainty contributed an average variance of $3.61 \mathrm{mV}^{2}$ (95\% confidence interval: $2.35-4.87 \mathrm{mV}^{2}$ ).

The genuine biological variability among ribbons was then determined by subtracting contributions from sources 1,2 and 3 from the overall ribbon-to-ribbon variability. We found that $16.4-22.8 \%$ of the overall ribbon-to-ribbon variance arises from cone-to-cone variance in $\mathrm{I}_{\mathrm{Ca}}$ (sources 1 and 2). Subtracting this contribution of cone-to-cone variance reduces ribbon-toribbon variance from $12.18 \mathrm{mV}^{2}$ to $9.50-10.23 \mathrm{mV}^{2}$. Subtracting the additional variance introduced by uncertainties in fitting $\mathrm{Ca}^{2+}$ responses (source 3: $3.61 \mathrm{mV}^{2}$ ) leaves an estimated genuine biological ribbon-to-ribbon variance of $5.89-6.62 \mathrm{mV}^{2}$ $(\mathrm{SD}=2.4-2.6 \mathrm{mV})$. Employing this same analysis with data obtained from experiments with the $\mathrm{Ca}^{2+}$ dye OGB-6F yielded a similar ribbon-to-ribbon variance $\left(5.96-6.48 \mathrm{mV}^{2}\right.$, $\mathrm{SD}=2.4-2.5 \mathrm{mV}$ ). This range of variability is consistent with the example in Figure $\mathbf{1}$ showing differences in $\mathrm{V}_{50}$ averaging $3.3 \mathrm{mV}$ between two ribbons in the same cone and indicates that the $\mathrm{V}_{50}$ values in a population of ribbons from a single cone are likely to span a range of at least $5.0 \mathrm{mV}$ $( \pm 1 \mathrm{SD})$.

While a $5 \mathrm{mV}$ range of $\mathrm{V}_{50}$ values may seem modest, an activation difference of this magnitude can alter $\mathrm{Ca}^{2+}$ influx by more than $45 \%$ when the cone is at a resting membrane potential in darkness of $-40 \mathrm{mV}$. This is illustrated by the theoretical $\mathrm{Ca}^{2+}$ response curves shown in Figure 7B. We simulated the voltage dependence of $\mathrm{I}_{\mathrm{Ca}}$ in cones using the average best-fit parameters of the $\mathrm{I}_{\mathrm{Ca}}$ curves shown in Figure 6B (dashed line in Figure $7 \mathbf{B}$ ), as well as curves with $\mathrm{V}_{50}$ values varying by $\pm 1 \mathrm{SD}$ from the mean $(\mathrm{SD}=2.5 \mathrm{mV}$, solid lines in Figure $7 \mathbf{B})$. At a membrane potential of $-40 \mathrm{mV}$, a ribbon exhibiting the more positive $\mathrm{Ca}^{2+}$ activation function $\left(\mathrm{V}_{50}=-35.6 \mathrm{mV}\right)$ that is $1 \mathrm{SD}$ above the mean would experience $45 \%$ less $\mathrm{Ca}^{2+}$ influx than a ribbon exhibiting a more negative activation function $\left(\mathrm{V}_{50}=-40.6 \mathrm{mV}\right)$ that is $1 \mathrm{SD}$ below the mean. Extending this analysis to consider $\mathrm{V}_{50}$ values $\pm 2 \mathrm{SD}$ away from the mean indicated a difference in $\mathrm{Ca}^{2+}$ influx of $70 \%$ or more. Nearly identical differences in $\mathrm{Ca}^{2+}$ influx were obtained using average parameters of the curves fit to optical ribbon $\mathrm{Ca}^{2+}$ measurements (i.e., Figure 6C). In addition to altering the $\mathrm{Ca}^{2+}$ influx at a given membrane potential, changes in $\mathrm{V}_{50}$ will also alter the slope of the relationship between voltage and $\mathrm{Ca}^{2+}$ influx, thereby altering synaptic gain. At any given membrane potential, the slope of this relationship will differ for ribbons exhibiting different $\mathrm{V}_{50}$ values, producing ribbon-to-ribbon differences in synaptic gain.

\section{Horizontal Cell Feedback Modulates $\mathrm{Ca}^{2+}$ Influx at Individual Ribbons Within Cones}

Inhibitory feedback from HCs regulates synaptic transmission from cones, contributing to the formation of center-surround receptive fields and color opponency in downstream retinal neurons (Thoreson and Mangel, 2012). Hyperpolarizing a HC, as occurs in light, reduces the peak amplitude of cone $\mathrm{I}_{\mathrm{Ca}}$ and shifts its activation positively by a few millivolts (Verweij et al., 1996). In the experiments described above, we measured intrinsic differences among ribbons while blocking inhibitory synaptic feedback from HCs to cones by using a superfusate lacking bicarbonate and strongly buffered with $10 \mathrm{mM}$ HEPES (Hirasawa and Kaneko, 2003). As a further test of the ability of cone ribbons to be regulated independently, we measured $\mathrm{Ca}^{2+}$ changes at individual ribbons while manipulating HC feedback during paired whole cell recordings between cones and postsynaptic HCs. For these experiments, we superfused the retinal slices with a bicarbonate-buffered medium that permits feedback (Warren et al., 2016a).

We compared ribbon $\mathrm{Ca}^{2+}$ responses when a postsynaptic $\mathrm{HC}$ was voltage clamped at either -9 or $-79 \mathrm{mV}$ (i.e., with active or inactive inhibitory feedback, respectively). Before imaging, we first confirmed electrophysiologically that HC-to-cone feedback was present by holding the cone at $-39 \mathrm{mV}$ for $2 \mathrm{~s}$ to activate $\mathrm{I}_{\mathrm{Ca}}$ and then hyperpolarizing the $\mathrm{HC}$ with a step from $-39 \mathrm{mv}$ to $-99 \mathrm{mV}$ to relieve inhibitory feedback. When feedback is present, hyperpolarizing the $\mathrm{HC}$ relieves feedback inhibition of cone $\mathrm{I}_{\mathrm{Ca}}$ and stimulates an inward current (Figure 8A; Warren et al., 2016b). Figure $\mathbf{8 B}$ shows $\mathrm{Ca}^{2+}$ responses measured simultaneously at three different ribbons in one cone, with and without negative feedback from the HC (red and black traces, respectively). In this example, depolarizing the $\mathrm{HC}$ to activate inhibitory feedback reduced the amplitude of $\mathrm{Ca}^{2+}$ influx at one ribbon (top set of traces) but not at the other two. Presumably, dendrites from the voltage-clamped $\mathrm{HC}$ did not contact the two non-responsive ribbons. The $\mathrm{Ca}^{2+}$ changes at the ribbon subject to HC feedback are plotted in Figure 8C and show that depolarization of the $\mathrm{HC}$ reduced the magnitude of $\mathrm{Ca}^{2+}$ influx at every cone test potential. By fitting Boltzmann functions to these activation profiles, we also found that the $\mathrm{V}_{50}$ shifted positively by $1.0 \mathrm{mV}$ when negative feedback was activated by depolarizing the HC. In this example, we held the HC at either -79 or $-9 \mathrm{mV}$ while testing cone responses over the entire voltage range (six replicate trials for each $\mathrm{HC}$ condition). Averaging multiple trials in this way reduced trial-to-trial changes in $\mathrm{Ca}^{2+}$ response amplitude.

In another approach to minimize trial-to-trial differences, we applied the same voltage step to some cones twice in succession, changing the $\mathrm{HC}$ holding potential from $-79 \mathrm{mV}$ to $-9 \mathrm{mV}$ (or vice versa) between the two steps (Figure 8D). In the example shown in Figure 8D, activating negative feedback by holding the $\mathrm{HC}$ at $-9 \mathrm{mV}$ strongly inhibited $\mathrm{Ca}^{2+}$ responses at this ribbon compared to responses evoked by the preceding test step applied when the HC was held at $-79 \mathrm{mV}$. Strong 
A

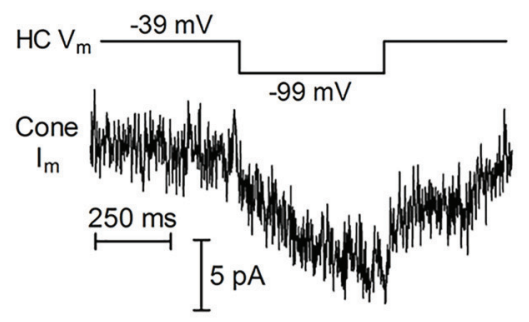

C

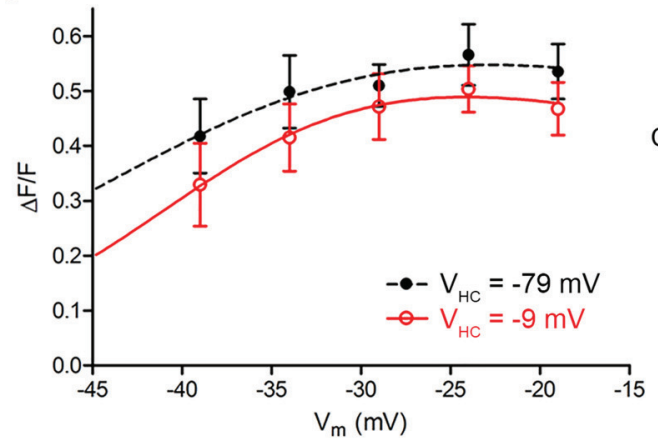

E

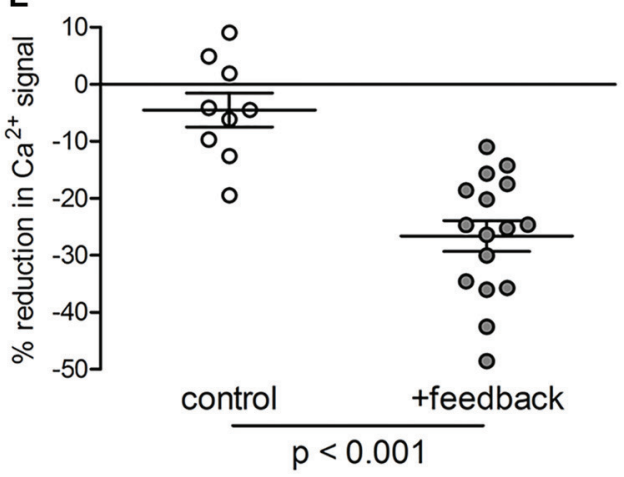

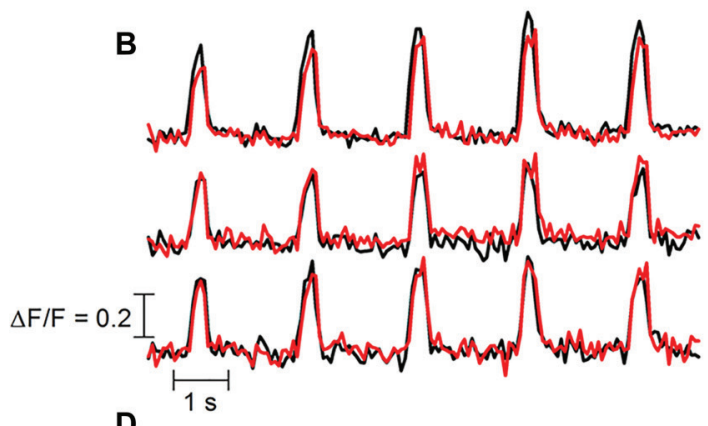

D

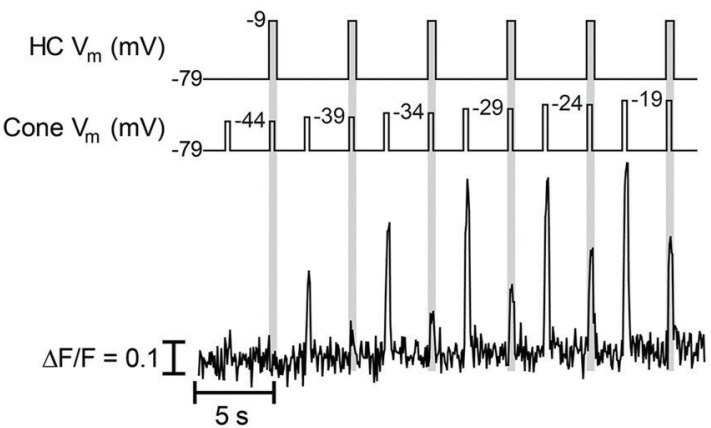

$\mathbf{F}$

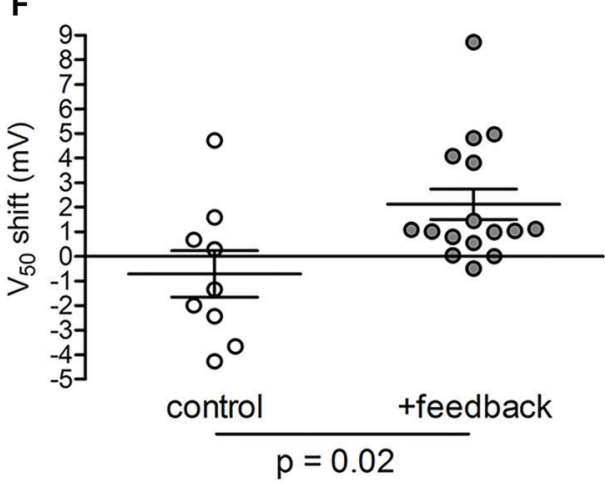

FIGURE 8 | Negative feedback from horizontal cells (HCs) modulates cone ribbons independently. (A) HC-induced feedback current for the cone with ribbon Ca ${ }^{2+}$ responses illustrated in panels $\mathbf{( B , C )}$. HC-to-cone feedback was confirmed electrophysiologically by holding the cone at $-39 \mathrm{mV}$ for $2 \mathrm{~s}$ to partially activate $\mathrm{I}_{\mathrm{Ca}}$ and then testing whether hyperpolarizing the $\mathrm{HC}$ with a step from $-39 \mathrm{mV}$ to $-99 \mathrm{mV}$ to relieve inhibitory feedback stimulated an inward current arising from an increase in cone $\mathrm{I}_{\mathrm{Ca}}$ (Warren et al., 2016b). (B) $\mathrm{Ca}^{2+}$ responses ( $\left.\Delta \mathrm{F} / \mathrm{F}\right)$ measured simultaneously from three ribbons in a cone. Black traces show control responses obtained when the $\mathrm{HC}$ was voltage clamped at $-79 \mathrm{mV}$. Red traces show responses obtained while activating inhibitory feedback to the cone by depolarizing the HC to $-9 \mathrm{mV}$. In this cone, only one of the three ribbons (top set of traces) showed a reduction in the amplitude of $\mathrm{Ca}^{2+}$ influx when negative feedback was activated by depolarizing the HC. (C) Average amplitude $(\Delta F / F)$ of $\mathrm{Ca}^{2+}$ signals plotted against cone membrane potential for the ribbon showing a feedback effect in panel (B). When negative feedback was activated by depolarizing the $\mathrm{HC}$ to $-9 \mathrm{mV}$, ribbon $\mathrm{Ca}^{2+}$ influx amplitude was decreased and the $\mathrm{V}_{50}$ shifted from $-39.7 \mathrm{mV}$ to $-38.7 \mathrm{mV}$. (D) Alternative stimulus protocol for testing HC-mediated feedback effects. This example shows an exemplar ribbon's Ca ${ }^{2+}$ responses during a sequence of depolarizing steps in the absence (white epochs) or presence (gray epochs) of inhibitory feedback from a simultaneously voltage-clamped HC. Test potentials delivered to the cone are indicated as Cone $\mathrm{V}_{\mathrm{m}}$. A second sequence was subsequently performed in this pair but with $\mathrm{HC}$ depolarization applied first rather than second for each test step pair delivered to the cone. Measurements from the two trials were averaged to calculate the feedback-mediated amplitude reduction and $V_{50}$ shift of $\mathrm{Ca}^{2+}$ responses at this ribbon. (E) Reduction in peak $\Delta \mathrm{F} / \mathrm{F}$ amplitude by $\mathrm{HC}$ negative feedback (feedback trials: $-26.6 \pm 10.6 \% ; p<0.001$, paired $t$-test; $n=16$ ribbons in 14 cones; control trials: $-3.7 \pm 12.6 \% ; p=0.4$, paired $t$-test; $n=9$ ribbons in 5 cones; $p<0.001$ between conditions, $t$-test). (F) Magnitude of $\mathrm{V}_{50}$ shift in ribbon $\mathrm{Ca}^{2+}$ signals induced by depolarizing $\mathrm{HCs}$ from $-79 \mathrm{mV}$ to $-9 \mathrm{mV}$ (feedback trials: $+2.1 \pm 2.5 \mathrm{mV} ; p<0.001$, paired $t$-test; $n=16$ ribbons in 14 cones; control trials: $-0.7 \pm 2.8 \mathrm{mV} ; p=0.5$, paired $t$-test; $n=9$ ribbons in 5 cones; $p=0.02$ between conditions, Mann Whitney test). Data are displayed as mean \pm SEM in panels (E,F).

inhibition of cone $\mathrm{Ca}^{2+}$ responses by inhibitory feedback from the $\mathrm{HC}$ in this example was evident despite the fact that in separate control trials conducted without a paired $\mathrm{HC}$, the second in a pair of depolarizing test steps applied to the cone sometimes evoked a larger response than the first. To quantify feedback-evoked changes in amplitude and voltage dependence, we eliminated possible order effects of this protocol by averaging two sequences in which we swapped the order in which we applied the $\mathrm{HC}$ voltage changes. In one sequence, the first cone test step was applied while feedback was activated by 
holding the $\mathrm{HC}$ at $-9 \mathrm{mV}$ and the second cone test step was applied while holding the $\mathrm{HC}$ at $-79 \mathrm{mV}$. In the other sequence, we reversed the order of $\mathrm{HC}$ test potentials to activate feedback during the second of each pair of cone test steps (e.g., Figure 8D).

Not every cone ribbon showed feedback-induced changes in $\mathrm{Ca}^{2+}$ signals. We saw feedback-evoked modulation at 16 out of 25 ribbons (64\%) in 14 cone-HC pairs in which the presence of feedback was confirmed electrophysiologically (e.g., Figure 8A). In four of these cone-HC pairs, we saw changes at one ribbon but not another in the same cone. For ribbons that exhibited a feedback effect, inducing negative feedback by depolarizing the HC from $-79 \mathrm{mV}$ to $-9 \mathrm{mV}$ caused a significant reduction in peak $\mathrm{Ca}^{2+}$ signal $\triangle \mathrm{F} / \mathrm{F}$ amplitude at the 16 responsive ribbons $(-26.6 \pm 10.6 \%, p<0.001)$. In identical control trials conducted without simultaneously voltage-clamped HCs, we saw no significant change in $\mathrm{Ca}^{2+}$ signal amplitude $(p=0.4)$; the difference between feedback and control conditions was significant (Figure 8E, $p<0.001$ ). Depolarizing HCs from $-79 \mathrm{mV}$ to $-9 \mathrm{mV}$ also caused a significant positive shift in $\mathrm{V}_{50}(+2.1 \pm 2.5 \mathrm{mV}, p<0.001)$ at ribbons sensitive to feedback, which differed significantly from control trials without a voltageclamped HC (Figure 8F, $p=0.02$ ). The ability of HCs to regulate $\mathrm{Ca}^{2+}$ signals at some ribbons but not others within a single cone provides further evidence that ribbons can operate in a functionally independent manner. Modulation by HC feedback could increase or diminish intrinsic differences in ribbon $\mathrm{Ca}^{2+}$ responses seen in the absence of feedback.

\section{DISCUSSION}

\section{Differences in Voltage Dependence and Amplitude of Ribbon $\mathrm{Ca}^{2+}$ Signals}

Our experiments reveal significant ribbon-to-ribbon differences in the voltage dependence of ribbon-associated $\mathrm{Ca}^{2+}$ signals. After accounting for technical variability in $\mathrm{Ca}^{2+}$ signal measurements and contributions from cone-to-cone variability in $\mathrm{I}_{\mathrm{Ca}}$, we found intrinsic variability (i.e., in the absence of inhibitory feedback from HCs) of $\mathrm{V}_{50}$ values among ribbonlocalized $\mathrm{Ca}^{2+}$ signals with a $\mathrm{SD}$ of $\sim 2.5 \mathrm{mV}$. Ribbon $\mathrm{V}_{50}$ values were normally distributed, suggesting that $68 \%( \pm 1 \mathrm{SD})$ of ribbons in a cone exhibit $\mathrm{V}_{50}$ values spanning a range of $5 \mathrm{mV}$. We found a similar degree of ribbon-to-ribbon variability using the higher affinity $\mathrm{Ca}^{2+}$ dye OGB-6F. Consistent with this range of $V_{50}$ values, we also observed reproducible $V_{50}$ differences of up to $3.5 \mathrm{mV}$ between neighboring ribbons in the same cone (e.g., Figure 1). Measurements of ribbon $\mathrm{Ca}^{2+}$ signals at two different $\mathrm{pH}$ values (7.6 and 7.8) confirmed that we could accurately detect $3 \mathrm{mV}$ changes in voltage dependence (Figure 5). Functional independence of ribbons was also demonstrated by manipulating $\mathrm{HC}$ membrane potential to alter the strength of HC to cone feedback and thereby produce reversible shifts in the $\mathrm{V}_{50}$ and amplitude of $\mathrm{Ca}^{2+}$ responses at individual cone ribbons. Small variations in positioning the focal plane of measurement or the size of ROIs did not contribute significantly to $\mathrm{V}_{50}$ variability. Although seemingly modest, differences in activation voltage of a few millivolts can have a significant impact on $\mathrm{Ca}^{2+}$ influx. A typical cone dark resting membrane potential of $-40 \mathrm{mV}$ places $\mathrm{I}_{\mathrm{Ca}}$ quite close to its activation midpoint. A difference in $\mathrm{V}_{50}$ values of $5 \mathrm{mV}$ about that mean $( \pm 1 \mathrm{SD})$ would produce a difference in $\mathrm{Ca}^{2+}$ influx of more than $45 \%$. Variation in the voltage dependence of whole-cell $\mathrm{I}_{\mathrm{Ca}}$ would also produce cone-to-cone differences in $\mathrm{Ca}^{2+}$ influx. Because release from cones is linearly related to $\mathrm{I}_{\mathrm{Ca}}$ (Jackman et al., 2009; Duncan et al., 2010; Bartoletti et al., 2011), ribbonto-ribbon differences in $\mathrm{Ca}^{2+}$ influx would be expected to produce differences in release exceeding $45 \%$ at the dark resting potential.

We first assessed intrinsic differences in $V_{50}$ variability among cone ribbons under conditions where inhibitory feedback from HCs to cones was blocked by use of the $\mathrm{pH}$ buffer HEPES (Hirasawa and Kaneko, 2003). In recordings where we allowed feedback to be active, directly depolarizing a voltageclamped HC to stimulate inhibitory feedback in a simultaneously voltage-clamped cone shifted $\mathrm{V}_{50}$ of $\mathrm{Ca}^{2+}$ signals at cone ribbons by an average of $+2.1 \mathrm{mV}$ and reduced the amplitude of ribbon-associated $\mathrm{Ca}^{2+}$ responses by an average of $27 \%$. HC feedback could therefore increase or diminish intrinsic differences in $\mathrm{Ca}^{2+}$ responses between individual ribbons in the same cone. Effects of feedback evoked by depolarizing a single $\mathrm{HC}$ were not exerted at every ribbon, but were instead restricted to a subset of ribbons within presynaptic cones.

We focused our study on differences in voltage dependence among ribbon-associated $\mathrm{Ca}^{2+}$ signals rather than amplitude. One major reason for this was that response amplitude measurements were more sensitive than $V_{50}$ measurements to differences in placement of the focal plane or delineation of the ROI (Figures 2, 3). However, some of the differences in response amplitude observed between ribbons were far too large to be explained by these technical factors, indicating that there are genuine differences in $\mathrm{Ca}^{2+}$ influx magnitude between ribbons. Genuine ribbon-to-ribbon differences in response amplitude were also shown by feedback experiments in which the amplitude of ribbon-associated $\mathrm{Ca}^{2+}$ signals could be reversibly inhibited at one ribbon but not another in the same cone by activating feedback from postsynaptic HCs (e.g., Figure 8).

Salamander cone terminals do not exhibit $\mathrm{Ca}^{2+}$-induced $\mathrm{Ca}^{2+}$ release from intracellular stores (unlike rods: Krizaj et al., 2003; Cadetti et al., 2006) nor do these terminals possess mitochondria (Linton et al., 2010). Local differences in mitochondrial $\mathrm{Ca}^{2+}$ uptake or release of $\mathrm{Ca}^{2+}$ from endoplasmic reticulum stores are therefore not likely to be responsible for differences in voltage dependence or amplitude among ribbon-style active zones in salamander cones. Instead, these differences are more likely due to variability in $\mathrm{Ca}^{2+}$ influx through L-type $\mathrm{Ca}^{2+}$ channels clustered beneath individual ribbons (tom Dieck et al., 2005; Cadetti et al., 2006; Lv et al., 2012).

In addition to modulation of $\mathrm{Ca}^{2+}$ signals by $\mathrm{HC}$ feedback, there are many factors that could contribute to intrinsic ribbon-to-ribbon differences in $\mathrm{Ca}^{2+}$ influx. Differences in 
$\mathrm{Ca}^{2+}$ response amplitude at different ribbons could arise from differences in the number of $\mathrm{Ca}^{2+}$ channels at each ribbon. But in addition, Éltes et al. (2017) found significant differences in $\mathrm{Ca}^{2+}$ influx at different hippocampal terminals that exceeded differences in $\mathrm{Ca}^{2+}$ channel number, suggesting that differences in the function or subunit composition of $\mathrm{Ca}^{2+}$ channels also contribute to differences among active zones. The main $\mathrm{Ca}^{2+}$ channel subtype in rod and cone photoreceptors is $\mathrm{Ca}_{V} 1.4$ but there is also evidence for Cav1.3 channels (Xiao et al., 2007). Both of these channel types possess splice variants with altered voltage dependence (Bock et al., 2011; Tan et al., 2011; Haeseleer et al., 2016). Due to differences in the C-terminal domain, $\mathrm{Ca}_{V} 1.4$ channels lack $\mathrm{Ca}^{2+}$-dependent inactivation (Wahl-Schott et al., 2006) and the inactivation properties of $\mathrm{Ca}_{V} 1.3$ channels can vary among cells (Scharinger et al., 2015). It was suggested that interactions between $\mathrm{Ca}^{2+}$ channels and accessory Gipc 3 proteins may contribute to observed differences in the voltage dependence of $\mathrm{Ca}^{2+}$ influx among ribbons in inner hair cells (Ohn et al., 2016). Similarly, differences in the voltage dependence and amplitude of $\mathrm{Ca}^{2+}$ signals at photoreceptor ribbons could potentially involve accessory proteins like CaBP4 (Haeseleer et al., 2004; Lee et al., 2014). Voltage dependence and conductance of photoreceptor $\mathrm{Ca}^{2+}$ channels can also be regulated by a host of neuromodulators including dopamine, cannabinoids, nitric oxide, somatostatin, fatty acids, and insulin (Stella and Thoreson, 2000; Vellani et al., 2000; Stella et al., 2001; Straiker and Sullivan, 2003; Kourennyi et al., 2004; Herrmann et al., 2011), the influence of which might vary among ribbons. $\mathrm{Ca}^{2+}$ channel voltage dependence and conductance are also regulated by local extracellular concentrations of $\mathrm{Ca}^{2+}, \mathrm{H}^{+}$, $\mathrm{Zn}^{2+}, \mathrm{Cl}^{-}$or $\mathrm{K}^{+}$ions (Wilkinson and Barnes, 1996; Cadetti et al., 2004; Cadetti and Thoreson, 2006; Babai and Thoreson, 2009). $\mathrm{Ca}^{2+}$ channels beneath ribbons are located at the apex of membrane invaginations that extend hundreds of nanometers into the cone terminal (Sterling and Matthews, 2005; tom Dieck et al., 2005; Lv et al., 2012). By isolating ribbon-associated $\mathrm{Ca}^{2+}$ channel clusters, this anatomical arrangement could promote local differences in the extracellular ionic microenvironment between invaginations. In the limited extracellular volume surrounding cone $\mathrm{Ca}^{2+}$ channels, small differences in the expression of a handful of ion channels, receptors, transporters, or binding partners could change the microenvironment enough to alter $\mathrm{Ca}^{2+}$ channel voltage dependence and channel conductance. Bipolar cells terminate in elaborately branched terminals possessing multiple presynaptic puncta (Euler et al., 2014). Ribbons at spatially distinct puncta in bipolar cells may also exhibit functional independence in their $\mathrm{Ca}^{2+}$ responses, especially given the relatively strong endogenous calcium buffers that are present in bipolar cells, equivalent to $1.2 \mathrm{mM}$ BAPTA (Burrone et al., 2002).

In addition to differences in $\mathrm{Ca}^{2+}$ responses among ribbons, we found variability in the voltage dependence of $\mathrm{I}_{\mathrm{Ca}}$ among cones, with a SD in $\mathrm{V}_{50}$ of $2.9 \mathrm{mV}$ after accounting for trial-to-trial variability. The variance introduced by residual uncompensated $\mathrm{R}_{\text {ser }}$ was negligible. In isolated rods, voltage dependence of $\mathrm{I}_{\mathrm{Ca}}$ shifted to more negative values over the first 3 min of whole cell recording as the pipette solution entered the cell (Corey et al., 1984). Time-dependent changes in voltage dependence may have contributed to the observed variability but we waited at least $3 \mathrm{~min}$ before making $\mathrm{Ca}^{2+}$ measurements and did not see consistent time-dependent changes. Differential effects of dopamine on $\mathrm{I}_{\mathrm{Ca}}$ in small single vs. large single cones in salamander retina indicate that different cone subtypes can possess different $\mathrm{Ca}^{2+}$ channel types or key modulators (Stella and Thoreson, 2000). Immunohistochemical differences among medium and short wavelength-sensitive cones of tree shrew retina also suggest that $\mathrm{Ca}^{2+}$ channel expression may differ among cone subtypes (Morgans, 1999). Although these studies suggest that some of the differences in $\mathrm{I}_{\mathrm{Ca}}$ voltage dependence we observed might arise from differences in $\mathrm{Ca}^{2+}$ channel subtypes or regulation among different classes of cones, we found no significant differences in $\mathrm{I}_{\mathrm{Ca}}$ voltage dependence among the three cone subtypes examined in our studies.

Consistent with ultrastructural studies (Pierantoni and McCann, 1984; Ahnelt et al., 1990; Sterling and Matthews, 2005; Pang et al., 2008), we found that the size of ribbons measured with fluorescently-conjugated RIBEYE-binding peptides can vary appreciably. In inner hair cells, $\mathrm{Ca}^{2+}$ signal amplitude varied significantly among ribbons, with larger ribbons attaining higher depolarization-evoked $\mathrm{Ca}^{2+}$ levels (Frank et al., 2009; Ohn et al., 2016). We did not find a correlation between ribbon size and $\mathrm{Ca}^{2+}$ response amplitude, but did find that ribbon size was strongly correlated with the spatial extent of $\mathrm{Ca}^{2+}$ signals (Figure 4). This suggests that the average density of functional $\mathrm{Ca}^{2+}$ channels along the extent of a ribbon, which has been estimated at $\sim 3$ channels per vesicle in the readily releasable pool (Bartoletti et al., 2010; Thoreson et al., 2016), is similar for different-sized ribbons. While larger ribbons did not necessarily exhibit larger peak $\mathrm{Ca}^{2+}$ responses, they nevertheless experienced greater total $\mathrm{Ca}^{2+}$ influx because of the larger area of $\mathrm{Ca}^{2+}$ entry.

\section{Functional Consequences of Ribbon Variability}

It has typically been thought that at the dark resting membrane potential, cone $\mathrm{I}_{\mathrm{Ca}}$ is near the foot of its activation function (Barnes and Kelly, 2002). However, we found an average $V_{50}$ for cone $\mathrm{I}_{\mathrm{Ca}}$ of $-38.1 \mathrm{mV}$, close to the average resting membrane potential for cones in darkness of $-40 \mathrm{mV}$ (Thoreson and Burkhardt, 1991). Because the $\mathrm{I}_{\mathrm{Ca}} /$ voltage activation curve is steepest at its $\mathrm{V}_{50}$, this arrangement is optimal for maximizing changes in release during small light-evoked changes in membrane voltage near darkness (Sterling and Laughlin, 2015). Such considerations also extend to local ribbon $\mathrm{Ca}^{2+}$ signals. At any given cone membrane potential, ribbons with $V_{50}$ values near the membrane potential would exhibit the largest changes in synaptic output for a small change in voltage. Ribbon-to-ribbon differences in the voltage dependence of $\mathrm{Ca}^{2+}$ influx would therefore allow some ribbons to respond with greater sensitivity to light-evoked voltage changes under dim illumination, when the cone membrane potential is more depolarized, and other ribbons to respond with greater sensitivity in bright conditions when cones are more hyperpolarized. Individual bipolar and HCs receive inputs from many cone ribbons. Receiving an ensemble 
of inputs from ribbons with varying but overlapping sensitivities could improve the ability of bipolar and HCs to respond to contrasts over a wide range of light intensities.

Release of a vesicle at cone ribbon synapses requires the opening of an average of only $2-3 \mathrm{Ca}^{2+}$ channels per vesicle (Bartoletti et al., 2011). A ribbon possessing more $\mathrm{Ca}^{2+}$ channels would be more likely to have an open channel and therefore release a vesicle at a given membrane voltage than a ribbon possessing fewer channels. This effectively makes ribbons with more $\mathrm{Ca}^{2+}$ channels more sensitive to small changes in membrane potential at hyperpolarized potentials, functioning much like a negative activation shift.

In the cochlea each postsynaptic spiral ganglion neuron contacts a single presynaptic inner hair cell ribbon, so variability among ribbons has been proposed to drive the diversity of spiking behaviors observed in spiral ganglion cells (Frank et al., 2009; Ohn et al., 2016). Unlike spiral ganglion neurons, bipolar and $\mathrm{HCs}$ in the retina receive inputs from many photoreceptor ribbons. It is therefore less likely that ribbonto-ribbon differences in $\mathrm{V}_{50}$ and amplitude of $\mathrm{Ca}^{2+}$ responses would produce significant differences in the responses of secondorder neurons (Burkhardt and Fahey, 1998; Burkhardt et al., 2006). To achieve such differences, the distribution a cell's ribbon inputs would have to be skewed towards more positive or negative potentials. Postsynaptic differences in bipolar cell anatomy and physiology are more likely to be responsible for differences in their response properties. A number of postsynaptic factors have been identified as contributing to differences in response characteristics among bipolar cells, including differential expression of glutamate receptors and ion channels, dendritic anatomy (e.g., dendritic extent and position of postsynaptic contacts relative to the ribbon), and influence of lateral feedback from HCs to bipolar cells (DeVries et al., 2006; Szmajda and Devries, 2011; Thoreson and Mangel, 2012; Puller et al., 2013; Euler et al., 2014; Lindstrom et al., 2014). Although ribbon-to-ribbon variability seems unlikely to be a major factor in generating response differences among bipolar cells, cone-to-cone differences in both resting membrane voltage and the voltage dependence of whole cell $\mathrm{I}_{\mathrm{Ca}}$ could produce differences among the responses of foveal midget bipolar cells in primate retina that receive inputs from only a single cone.

Endogenous $\mathrm{Ca}^{2+}$ buffering in cones is surprisingly weak, equivalent to only 50-100 $\mu$ M EGTA (Van Hook and Thoreson, 2014). To improve the spatial resolution for detection of $\mathrm{Ca}^{2+}$ signals by confocal microscopy at individual ribbons, we used a higher concentration of EGTA $(5 \mathrm{mM})$. Fast release of membrane-associated vesicles, as might occur during a rapid decrement in light, is regulated by $\mathrm{Ca}^{2+}$ within highly localized nanodomains $<100 \mathrm{~nm}$ from $\mathrm{Ca}^{2+}$ channels even in the presence of weak exogenous buffering (Mercer et al., 2011; Van Hook and Thoreson, 2015). On the other hand, the slower sustained release that dominates in darkness is governed more strongly by the rate at which vesicles can be delivered to ribbons and ribbon-release sites (Jackman et al., 2009). The replenishment process that controls sustained release is itself regulated by $\mathrm{Ca}^{2+}$ acting at ribbon-associated sites located a few hundred nanometers above $\mathrm{Ca}^{2+}$ channels, and so sustained release is much more sensitive than fast release to $\mathrm{Ca}^{2+}$ buffering and global $\mathrm{Ca}^{2+}$ levels (Babai et al., 2010; Vaithianathan and Matthews, 2014; Van Hook et al., 2014; Van Hook and Thoreson, 2015). The impact of ribbon-toribbon differences in $\mathrm{Ca}^{2+}$ entry would therefore diminish during sustained release that occurs under conditions of dim illumination when $\mathrm{Ca}^{2+}$ levels are elevated similarly throughout the terminal.

HC activity is governed by glutamatergic inputs from presynaptic photoreceptors. Although there is controversy about the underlying mechanisms (Kramer and Davenport, 2015), there is an emerging consensus that changes in voltage dependence and amplitude of $\mathrm{Ca}^{2+}$ influx in cones caused by $\mathrm{HC}$ feedback involves extracellular proton levels within the synaptic cleft (Barnes and Bui, 1991; Hirasawa and Kaneko, 2003; Cadetti and Thoreson, 2006; Kemmler et al., 2014; Vroman et al., 2014; Warren et al., 2016a). Not every ribbon within a cone terminal was subject to feedback regulation from a single postsynaptic $\mathrm{HC}$ in our experiments. However, we found that $64 \%$ of the ribbons we analyzed in synaptically-connected cone-HC pairs were sensitive to feedback from a single postsynaptic HC. This was a higher percentage than predicted from previous work suggesting that a single $\mathrm{HC}$ in salamander retinal slices makes an average of 2.1 synaptic ribbon contacts per presynaptic cone (Bartoletti et al., 2010). Because salamander cones possess an average of 13 ribbons per cell (Bartoletti et al., 2010), we expected to see detectable feedback effects in fewer than $20 \%$ of ribbons. Furthermore, if only the few ribbons that directly contact an individual HC were influenced by its feedback, we would predict that the impact of feedback on whole cell $\mathrm{I}_{\mathrm{Ca}}$ - which is the summed currents from all the ribbons-would be less than $20 \%$ of the impact on $\mathrm{Ca}^{2+}$ responses at single ribbons. Instead, feedback-induced changes in the amplitude and voltage dependence of whole-cell $\mathrm{I}_{\mathrm{Ca}}$ measured under similar experimental conditions in paired cone-HC recordings (Warren et al., 2016a) were only slightly smaller than changes observed at individual ribbons in the present study. The unexpectedly high prevalence of feedback effects suggests that the strong HC depolarization used to elicit negative feedback in these experiments may have spread through gap junctions to nearby coupled HCs, allowing feedback effects to become evident at ribbons that were not directly contacted by dendrites of the voltage-clamped HC. Much of the HC network is excised by slicing the retina into vertical sections, suggesting that this signal spread is likely to occur close to the recipient cone. The spread of voltage from one $\mathrm{HC}$ to another may contribute to the slower components of feedback seen in response to an abrupt change in HC membrane potential (Figure 8A; see also Warren et al., 2016b). These findings suggest that feedback effects from individual HCs are amplified by local interactions among HCs at photoreceptor synapses.

Our results show that $\mathrm{Ca}^{2+}$ signals at individual synaptic ribbons in cone photoreceptors can vary significantly from one another in both amplitude and voltage dependence. $\mathrm{V}_{50}$ values of ribbons within single cochlear inner hair cells varied with a SD of $3.2 \mathrm{mV}$ (Frank et al., 2009; Ohn et al., 2016). 
Voltage dependence of inner hair cell ribbons also varied with subcellular location, with active zones on the modiolar side of inner hair cells activating at more positive voltages than pillar active zones. Thus, at least some of the differences among hair cell ribbons must arise from non-random processes (Ohn et al., 2016). Our results show that $\mathrm{Ca}^{2+}$ influx at individual cone ribbons can be rapidly and actively regulated by $\mathrm{HC}$ feedback in a non-random fashion. Intrinsic ribbon-to-ribbon differences in cones may also be actively regulated by cellular processes operating on a slow time scale. Alternatively, they may simply result from random differences in the expression and delivery of proteins to different parts of the cone. Regardless, ribbon-to-ribbon differences in $\mathrm{Ca}^{2+}$ signals expand the range of transformations available to cones for converting light-evoked voltage responses into synaptic release, and can thus expand the range of information provided to downstream neurons about changing light levels.

\section{REFERENCES}

Ahnelt, P., Keri, C., and Kolb, H. (1990). Identification of pedicles of putative blue-sensitive cones in the human retina. J. Comp. Neurol. 293, 39-53. doi: 10.1002/cne.902930104

Babai, N., Bartoletti, T. M., and Thoreson, W. B. (2010). Calcium regulates vesicle replenishment at the cone ribbon synapse. J. Neurosci. 30, 15866-15877. doi: 10.1523/JNEUROSCI.2891-10.2010

Babai, N., and Thoreson, W. B. (2009). Horizontal cell feedback regulates calcium currents and intracellular calcium levels in rod photoreceptors of salamander and mouse retina: horizontal cell to rod feedback in salamander and mouse retina. J Physiol. 587, 2353-2364. doi: 10.1113/jphysiol.2009. 169656

Barnes, S., and Bui, Q. (1991). Modulation of calcium-activated chloride current via $\mathrm{pH}$-induced changes of calcium channel properties in cone photoreceptors. J. Neurosci. 11, 4015-4023.

Barnes, S., and Hille, B. (1989). Ionic channels of the inner segment of tiger salamander cone photoreceptors. J. Gen. Physiol. 94, 719-743. doi: 10.1085/jgp. 94.4.719

Barnes, S., and Kelly, M. E. M. (2002). Calcium channels at the photoreceptor synapse. Adv. Exp. Med. Biol. 514, 465-476. doi: 10.1007/978-1-46150121-3_28

Barnes, S., Merchant, V., and Mahmud, F. (1993). Modulation of transmission gain by protons at the photoreceptor output synapse. Proc. Natl. Acad. Sci. U S A 90, 10081-10085. doi: 10.1073/pnas.90.21.10081

Bartoletti, T. M., Babai, N., and Thoreson, W. B. (2010). Vesicle pool size at the salamander cone ribbon synapse. J. Neurophysiol. 103, 419-423. doi: 10.1152/jn.00718.2009

Bartoletti, T. M., Jackman, S. L., Babai, N., Mercer, A. J., Kramer, R. H., and Thoreson, W. B. (2011). Release from the cone ribbon synapse under bright light conditions can be controlled by the opening of only a few $\mathrm{Ca}^{2+}$ channels. J. Neurophysiol. 106, 2922-2935. doi: 10.1152/jn.00634.2011

Bock, G., Gebhart, M., Scharinger, A., Jangsangthong, W., Busquet, P., Poggiani, C., et al. (2011). Functional properties of a newly identified C-terminal splice variant of Cav1.3 L-type $\mathrm{Ca}^{2+}$ channels. J. Biol. Chem. 286, 42736-42748. doi: 10.1074/jbc.m111.269951

Brandt, A., Khimich, D., and Moser, T. (2005). Few Cav 1.3 channels regulate the exocytosis of a synaptic vesicle at the hair cell ribbon synapse. J. Neurosci. 25, 11577-11585. doi: 10.1523/jneurosci.3411-05.2005

Burkhardt, D. A., and Fahey, P. K. (1998). Contrast enhancement and distributed encoding by bipolar cells in the retina. J. Neurophysiol. 80, 1070-1081.

Burkhardt, D. A., Fahey, P. K., and Sikora, M. A. (2006). Natural images and contrast encoding in bipolar cells in the retina of the land- and aquaticphase tiger salamander. Vis. Neurosci. 23, 35-47. doi: 10.1017/s095252380 6231043

\section{AUTHOR CONTRIBUTIONS}

Both authors designed experiments, conducted experiments, analyzed data and wrote the article.

\section{FUNDING}

This study was supported by the National Eye Institute, National Institutes of Health grant EY010542 (WBT), Research to Prevent Blindness Senior Scientific Investigator Award (WBT), UNMC graduate assistantship (JJG) and Purdue Pharma Scholars Fellowship (JJG).

\section{ACKNOWLEDGMENTS}

We thank Dr. David Zenisek for the gift of RIBEYE-binding peptides and Dr. Matthew Van Hook for helpful discussion.

Burrone, J., Neves, G., Gomis, A., Cooke, A., and Lagnado, L. (2002) Endogenous calcium buffers regulate fast exocytosis in the synaptic terminal of retinal bipolar cells. Neuron 33, 101-112. doi: 10.1016/s0896-6273 (01)00565-7

Cadetti, L., Bryson, E. J., Ciccone, C. A., Rabl, K., and Thoreson, W. B. (2006). Calcium-induced calcium release in rod photoreceptor terminals boosts synaptic transmission during maintained depolarization. Eur. J. Neurosci. 23, 2983-2990. doi: 10.1111/j.1460-9568.2006.04845.x

Cadetti, L., and Thoreson, W. B. (2006). Feedback effects of horizontal cell membrane potential on cone calcium currents studied with simultaneous recordings. J. Neurophysiol. 95, 1992-1995. doi: 10.1152/jn.01042.2005

Cadetti, L., Thoreson, W. B., and Piccolino, M. (2004). Pre- and post-synaptic effects of manipulating surface charge with divalent cations at the photoreceptor synapse. Neuroscience 129, 791-801. doi: 10.1016/j. neuroscience.2004.08.043

Carter-Dawson, L. D., and LaVail, M. M. (1979). Rods and cones in the mouse retina. I. Structural analysis using light and electron microscopy. J. Comp. Neurol. 188, 245-262. doi: 10.1002/cne.901880204

Choi, S.-Y., Jackman, S., Thoreson, W. B., and Kramer, R. H. (2008). Light regulation of $\mathrm{Ca}^{2+}$ in the cone photoreceptor synaptic terminal. Vis. Neurosci. 25, 693-700. doi: 10.1017/s0952523808080814

Corey, D. P., Dubinsky, J. M., and Schwartz, E. A. (1984). The calcium current in inner segments of rods from the salamander (Ambystoma tigrinum) retina. J. Physiol. 354, 557-575. doi: 10.1113/jphysiol.1984. sp015393

DeVries, S. H., Li, W., and Saszik, S. (2006). Parallel processing in two transmitter microenvironments at the cone photoreceptor synapse. Neuron 50, 735-748. doi: 10.1016/j.neuron.2006.04.034

Duncan, G., Rabl, K., Gemp, I., Heidelberger, R., and Thoreson, W. B. (2010) Quantitative analysis of synaptic release at the photoreceptor synapse. Biophys. J. 98, 2102-2110. doi: 10.1016/j.bpj.2010.02.003

Eggermann, E., Bucurenciu, I., Goswami, S. P., and Jonas, P. (2011). Nanodomain coupling between $\mathrm{Ca}^{2+}$ channels and sensors of exocytosis at fast mammalian synapses. Nat. Rev. Neurosci. 13, 7-21. doi: 10.1038/nr n3125

Éltes, T., Kirizs, T., Nusser, Z., and Holderith, N. (2017). Target cell type-dependent differences in $\mathrm{Ca}^{2+}$ channel function underlie distinct release probabilities at hippocampal glutamatergic terminals. J. Neurosci. 37, 1910-1924. doi: 10.1523/jneurosci.2024-16.2017

Euler, T., Haverkamp, S., Schubert, T., and Baden, T. (2014). Retinal bipolar cells: elementary building blocks of vision. Nat. Rev. Neurosci. 15, 507-519. doi: 10.1038/nrn3783

Frank, T., Khimich, D., Neef, A., and Moser, T. (2009). Mechanisms contributing to synaptic $\mathrm{Ca}^{2+}$ signals and their heterogeneity in hair cells. Proc. Natl. Acad. Sci. US A 106, 4483-4488. doi: 10.1073/pnas.0813213106 
Goutman, J. D., and Glowatzki, E. (2007). Time course and calcium dependence of transmitter release at a single ribbon synapse. Proc. Natl. Acad. Sci. U S A 104, 16341-16346. doi: 10.1073/pnas.0705756104

Graydon, C. W., Zhang, J., Oesch, N. W., Sousa, A. A., Leapman, R. D., and Diamond, J. S. (2014). Passive diffusion as a mechanism underlying ribbon synapse vesicle release and resupply. J. Neurosci. 34, 8948-8962. doi: 10.1523/jneurosci.1022-14.2014

Haeseleer, F., Imanishi, Y., Maeda, T., Possin, D. E., Maeda, A., Lee, A., et al. (2004). Essential role of $\mathrm{Ca}^{2+}$-binding protein 4, a Cav1.4 channel regulator, in photoreceptor synaptic function. Nat. Neurosci. 7, 1079-1087. doi: $10.1038 / \mathrm{nn} 1320$

Haeseleer, F., Williams, B., and Lee, A. (2016). Characterization of C-terminal splice variants of Cav1.4 $\mathrm{Ca}^{2+}$ channels in human retina. J. Biol. Chem. 291, 15663-15673. doi: 10.1074/jbc.M116.731737

Herrmann, R., Heflin, S. J., Hammond, T., Lee, B., Wang, J., Gainetdinov, R. R., et al. (2011). Rod vision is controlled by dopamine-dependent sensitization of rod bipolar cells by GABA. Neuron 72, 101-110. doi: 10.1016/j.neuron. 2011.07.030

Hirasawa, H., and Kaneko, A. (2003). pH changes in the invaginating synaptic cleft mediate feedback from horizontal cells to cone photoreceptors by modulating $\mathrm{Ca}^{2+}$ channels. J. Gen. Physiol. 122, 657-671. doi: 10.1085/jgp.200308863

Iijima, T., Ciani, S., and Hagiwara, S. (1986). Effects of the external pH on Ca channels: experimental studies and theoretical considerations using a two-site, two-ion model. Proc. Natl. Acad. Sci. U S A 83, 654-658. doi: 10.1073/pnas. 83.3.654

Jackman, S. L., Choi, S.-Y., Thoreson, W. B., Rabl, K., Bartoletti, T. M., and Kramer, R. H. (2009). Role of the synaptic ribbon in transmitting the cone light response. Nat. Neurosci. 12, 303-310. doi: 10.1038/nn.2267

Jarsky, T., Tian, M., and Singer, J. H. (2010). Nanodomain control of exocytosis is responsible for the signaling capability of a retinal ribbon synapse. J. Neurosci. 30, 11885-11895. doi: 10.1523/jneurosci.1415-10.2010

Kemmler, R., Schultz, K., Dedek, K., Euler, T., and Schubert, T. (2014). Differential regulation of cone calcium signals by different horizontal cell feedback mechanisms in the mouse retina. J. Neurosci. 34, 11826-11843. doi: 10.1523/jneurosci.0272-14.2014

Kourennyi, D. E., Liu, X., Hart, J., Mahmud, F., Baldridge, W. H., and Barnes, S. (2004). Reciprocal modulation of calcium dynamics at rod and cone photoreceptor synapses by nitric oxide. J. Neurophysiol. 92, 477-483. doi: $10.1152 /$ jn.00606.2003

Krafte, D. S., and Kass, R. S. (1988). Hydrogen ion modulation of Ca channel current in cardiac ventricular cells. Evidence for multiple mechanisms. J. Gen. Physiol. 91, 641-657. doi: 10.1085/jgp.91.5.641

Kramer, R. H., and Davenport, C. M. (2015). Lateral inhibition in the vertebrate retina: the case of the missing neurotransmitter. PLoS Biol. 13:e1002322. doi: 10.1371/journal.pbio.1002322

Krizaj, D., Lai, F. A., and Copenhagen, D. R. (2003). Ryanodine stores and calcium regulation in the inner segments of salamander rods and cones. J. Physiol. 547, 761-774. doi: 10.1113/jphysiol.2002.035683

Lee, A., Fakler, B., Kaczmarek, L. K., and Isom, L. L. (2014). More than a pore: ion channel signaling complexes. J. Neurosci. 34, 15159-15169. doi: 10.1523/jneurosci.3275-14.2014

Lindstrom, S. H., Ryan, D. G., Shi, J., and DeVries, S. H. (2014). Kainate receptor subunit diversity underlying response diversity in retinal off bipolar cells. J. Physiol. 592, 1457-1477. doi: 10.1113/jphysiol.2013.265033

Linton, J. D., Holzhausen, L. C., Babai, N., Song, H., Miyagishima, K. J., Stearns, G. W., et al. (2010). Flow of energy in the outer retina in darkness and in light. Proc. Natl. Acad. Sci. U S A 107, 8599-8604. doi: 10.1073/pnas. 1002471107

Lv, C., Gould, T. J., Bewersdorf, J., and Zenisek, D. (2012). High-resolution optical imaging of zebrafish larval ribbon synapse protein RIBEYE, RIM2, and CaV1.4 by stimulation emission depletion microscopy. Microsc. Microanal. 18, 745-752. doi: 10.1017/s1431927612000268

Lv, C., Stewart, W. J., Akanyeti, O., Frederick, C., Zhu, J., Santos-Sacchi, J., et al. (2016). Synaptic ribbons require ribeye for electron density, proper synaptic localization, and recruitment of calcium channels. Cell Rep. 15, 2784-2795. doi: 10.1016/j.celrep.2016.05.045

Mansergh, F., Orton, N. C., Vessey, J. P., Lalonde, M. R., Stell, W. K., Tremblay, F., et al. (2005). Mutation of the calcium channel gene Cacnalf disrupts calcium signaling, synaptic transmission and cellular organization in mouse retina. Hum. Mol. Genet. 14, 3035-3046. doi: 10.1093/hmg/ ddi336

Mariani, A. P. (1986). Photoreceptors of the larval tiger salamander retina. Proc. R. Soc. Lond. B Biol. Sci. 227, 483-492. doi: 10.1098/rspb.19 86.0035

Maxeiner, S., Luo, F., Tan, A., Schmitz, F., and Südhof, T. C. (2016). How to make a synaptic ribbon: RIBEYE deletion abolishes ribbons in retinal synapses and disrupts neurotransmitter release. EMBO J. 35, 1098-1114. doi: 10.15252/embj. 201592701

Mercer, A. J., Rabl, K., Riccardi, G. E., Brecha, N. C., Stella, S. L. Jr., and Thoreson, W. B. (2011). Location of release sites and calcium-activated chloride channels relative to calcium channels at the photoreceptor ribbon synapse. J. Neurophysiol. 105, 321-335. doi: 10.1152/jn.003 32.2010

Mercer, A. J., and Thoreson, W. B. (2011). The dynamic architecture of photoreceptor ribbon synapses: cytoskeletal, extracellular matrix and intramembrane proteins. Vis. Neurosci. 28, 453-471. doi: $10.1017 / \mathrm{s} 0952523811000356$

Morgans, C. W. (1999). Calcium channel heterogeneity among cone photoreceptors in the tree shrew retina. Eur. J. Neurosci. 11, 2989-2993. doi: 10.1046/j.1460-9568.1999.00719.x

Ohn, T.-L., Rutherford, M. A., Jing, Z., Jung, S., Duque-Afonso, C. J., Hoch, G., et al. (2016). Hair cells use active zones with different voltage dependence of $\mathrm{Ca}^{2+}$ influx to decompose sounds into complementary neural codes. Proc. Natl. Acad. Sci. U S A 113, E4716-E4725. doi: 10.1073/pnas.16057 37113

Pang, J.-J., Gao, F., Barrow, A., Jacoby, R. A., and Wu, S. M. (2008). How do tonic glutamatergic synapses evade receptor desensitization? J. Physiol. 586, 2889-2902. doi: 10.1113/jphysiol. 2008.151050

Pierantoni, R. L., and McCann, G. D. (1984). "A quantitative study on synaptic ribbons in the photoreceptors of turtle and frog," in Photoreceptors, eds. A. Borsellino and L. Cervetto (Boston, MA: Springer), 255-283.

Puller, C., Ivanova, E., Euler, T., Haverkamp, S., and Schubert, T. (2013). OFF bipolar cells express distinct types of dendritic glutamate receptors in the mouse retina. Neuroscience 243, 136-148. doi: 10.1016/j.neuroscience. 2013.03.054

Rabl, K., and Thoreson, W. B. (2002). Calcium-dependent inactivation and depletion of synaptic cleft calcium ions combine to regulate rod calcium currents under physiological conditions. Eur. J. Neurosci. 16, 2070-2077. doi: 10.1046/j.1460-9568.2002.02277.x

Scharinger, A., Eckrich, S., Vandael, D. H., Schönig, K., Koschak, A., Hecker, D., et al. (2015). Cell-type-specific tuning of Cav1.3 $\mathrm{Ca}^{2+}$-channels by a C-terminal automodulatory domain. Front. Cell. Neurosci. 9:309. doi: 10.3389/fncel.2015. 00309

Schmitz, F. (2009). The making of synaptic ribbons: how they are built and what they do. Neuroscientist 15, 611-624. doi: 10.1177/107385840 9340253

Sherman, A. J., Shrier, A., and Cooper, E. (1999). Series resistance compensation for whole-cell patch-clamp studies using a membrane state estimator. Biophys. J. 77, 2590-2601. doi: 10.1016/s0006-3495 (99)77093-1

Sherry, D. M., Bui, D. D., and Degrip, W. J. (1998). Identification and distribution of photoreceptor subtypes in the neotenic tiger salamander retina. Vis. Neurosci. 15, 1175-1187. doi: 10.1017/s0952523898 156201

Stella, S. L., Bryson, E. J., and Thoreson, W. B. (2001). Insulin inhibits voltagedependent calcium influx into rod photoreceptors. Neuroreport 12, 947-951. doi: 10.1097/00001756-200104170-00017

Stella, S. L., and Thoreson, W. B. (2000). Differential modulation of rod and cone calcium currents in tiger salamander retina by D2 dopamine receptors and cAMP. Eur. J. Neurosci. 12, 3537-3548. doi: 10.1046/j.1460-9568. 2000.00235.x

Sterling, P., and Laughlin, S. (2015). Principles of Neural Design. Cambridge, MA: MIT Press.

Sterling, P., and Matthews, G. (2005). Structure and function of ribbon synapses. Trends Neurosci. 28, 20-29. doi: 10.1016/j.tins.2004.11.009 
Straiker, A., and Sullivan, J. M. (2003). Cannabinoid receptor activation differentially modulates ion channels in photoreceptors of the tiger salamander. J. Neurophysiol. 89, 2647-2654. doi: 10.1152/jn.00268.2002

Szmajda, B. A., and Devries, S. H. (2011). Glutamate spillover between mammalian cone photoreceptors. J. Neurosci. 31, 13431-13441. doi: 10.1523/jneurosci. 2105-11.2011

Tan, B. Z., Jiang, F., Tan, M. Y., Yu, D., Huang, H., Shen, Y., et al. (2011). Functional characterization of alternative splicing in the $\mathrm{C}$ terminus of L-type CaV1.3 channels. J. Biol. Chem. 286, 42725-42735. doi: 10.1074/jbc.M111. 265207

Thoreson, W. B., and Burkhardt, D. A. (1991). Ionic influences on the prolonged depolarization of turtle cones in situ. J. Neurophysiol. 65, 96-110.

Thoreson, W. B., and Mangel, S. C. (2012). Lateral interactions in the outer retina. Prog. Retin. Eye Res. 31, 407-441. doi: 10.1016/j.preteyeres. 2012.04.003

Thoreson, W. B., Van Hook, M. J., Parmelee, C., and Curto, C. (2016). Modeling and measurement of vesicle pools at the cone ribbon synapse: changes in release probability are solely responsible for voltage-dependent changes in release. Synapse 70, 1-14. doi: 10.1002/syn.21871

tom Dieck, S., Altrock, W. D., Kessels, M. M., Qualmann, B., Regus, H., Brauner, D., et al. (2005). Molecular dissection of the photoreceptor ribbon synapse: physical interaction of Bassoon and RIBEYE is essential for the assembly of the ribbon complex. J. Cell Biol. 168, 825-836. doi: 10.1083/jcb. 200408157

Vaithianathan, T., and Matthews, G. (2014). Visualizing synaptic vesicle turnover and pool refilling driven by calcium nanodomains at presynaptic active zones of ribbon synapses. Proc. Natl. Acad. Sci. U S A 111, 8655-8660. doi: 10.1073/pnas. 1323962111

Van Hook, M. J., and Thoreson, W. B. (2013). Simultaneous whole-cell recordings from photoreceptors and second-order neurons in an amphibian retinal slice preparation. J. Vis. Exp. 76:e50007. doi: 10.3791/50007

Van Hook, M. J., and Thoreson, W. B. (2014). Endogenous calcium buffering at photoreceptor synaptic terminals in salamander retina. Synapse 68, 518-528. doi: 10.1002/syn. 21768

Van Hook, M. J., and Thoreson, W. B. (2015). Weak endogenous $\mathrm{Ca}^{2+}$ buffering supports sustained synaptic transmission by distinct mechanisms in rod and cone photoreceptors in salamander retina. Physiol. Rep. 3:e12567. doi: 10.14814/phy2.12567

Van Hook, M. J., Parmelee, C. M., Chen, M., Cork, K. M., Curto, C., and Thoreson, W. B. (2014). Calmodulin enhances ribbon replenishment and shapes filtering of synaptic transmission by cone photoreceptors. J. Gen. Physiol. 144, 357-378. doi: 10.1085/jgp.201411229

Vellani, V., Reynolds, A. M., and McNaughton, P. A. (2000). Modulation of the synaptic $\mathrm{Ca}^{2+}$ current in salamander photoreceptors by polyunsaturated fatty acids and retinoids. J. Physiol. 529, 333-344. doi: 10.1111/j.1469-7793.2000. 00333.x
Verweij, J., Kamermans, M., and Spekreijse, H. (1996). Horizontal cells feed back to cones by shifting the cone calcium-current activation range. Vision Res. 36, 3943-3953. doi: 10.1016/s0042-6989(96)00142-3

Vroman, R., Klaassen, L. J., Howlett, M. H. C., Cenedese, V., Klooster, J., Sjoerdsma, T., et al. (2014). Extracellular ATP hydrolysis inhibits synaptic transmission by increasing ph buffering in the synaptic cleft. PLoS Biol. 12:e1001864. doi: 10.1371/journal.pbio.1001864

Wahl-Schott, C., Baumann, L., Cuny, H., Eckert, C., Griessmeier, K., and Biel, M. (2006). Switching off calcium-dependent inactivation in L-type calcium channels by an autoinhibitory domain. Proc. Natl. Acad. Sci. U S A 103, 15657-15662. doi: 10.1073/pnas.0604621103

Warren, T. J., Van Hook, M. J., Supuran, C. T., and Thoreson, W. B. (2016a). Sources of protons and a role for bicarbonate in inhibitory feedback from horizontal cells to cones in Ambystoma tigrinum retina. J. Physiol. 594, 6661-6677. doi: 10.1113/JP272533

Warren, T. J., Van Hook, M. J., Tranchina, D., and Thoreson, W. B. (2016b). Kinetics of inhibitory feedback from horizontal cells to photoreceptors: implications for an ephaptic mechanism. J. Neurosci. 36, 10075-10088. doi: 10.1523/JNEUROSCI.1090-16.2016

Wilkinson, M. F., and Barnes, S. (1996). The dihydropyridine-sensitive calcium channel subtype in cone photoreceptors. J. Gen. Physiol. 107, 621-630. doi: 10.1085/jgp.107.5.621

Xiao, H., Chen, X., and Steele, E. C. Jr. (2007). Abundant L-type calcium channel $\mathrm{Ca}(\mathrm{v}) 1.3$ (alpha1D) subunit mRNA is detected in rod photoreceptors of the mouse retina via in situ hybridization. Mol. Vis. 13, 764-771. Available online at: http://www.molvis.org/molvis/v13/a83/

$\mathrm{Xu}$, J. W., and Slaughter, M. M. (2005). Large-conductance calciumactivated potassium channels facilitate transmitter release in salamander rod synapse. J. Neurosci. 25, 7660-7668. doi: 10.1523/JNEUROSCI.157205.2005

Zenisek, D., Davila, V., Wan, L., and Almers, W. (2003). Imaging calcium entry sites and ribbon structures in two presynaptic cells. J. Neurosci. 23, 2538-2548.

Zenisek, D., Horst, N. K., Merrifield, C., Sterling, P., and Matthews, G. (2004). Visualizing synaptic ribbons in the living cell. J. Neurosci. 24, 9752-9759. doi: 10.1523/JNEUROSCI.2886-04.2004

Conflict of Interest Statement: The authors declare that the research was conducted in the absence of any commercial or financial relationships that could be construed as a potential conflict of interest.

Copyright (C) 2017 Grassmeyer and Thoreson. This is an open-access article distributed under the terms of the Creative Commons Attribution License (CC BY). The use, distribution or reproduction in other forums is permitted, provided the original author(s) or licensor are credited and that the original publication in this journal is cited, in accordance with accepted academic practice. No use, distribution or reproduction is permitted which does not comply with these terms. 